Pontifícia Universidade $C_{\text {atólica }}$

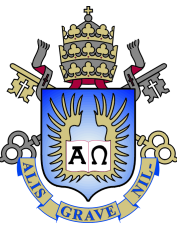

Vitor Gabriel Rivas Martello

Pre-FOMC Announcement Relief

Dissertação de Mestrado

Dissertation presented to the Programa de Pós-graduação em Economia of PUC-Rio in partial fulfillment of the requirements for the degree of Mestre em Economia.

Advisor: Prof. Ruy Monteiro Ribeiro 


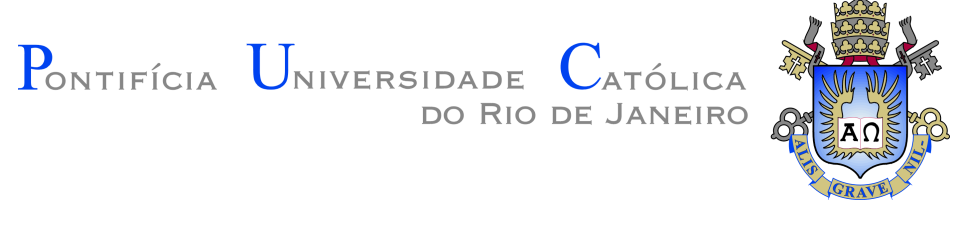

Vitor Gabriel Rivas Martello

\section{Pre-FOMC Announcement Relief}

Dissertation presented to the Programa de Pós-graduação em Economia of PUC-Rio in partial fulfillment of the requirements for the degree of Mestre em Economia. Approved by the undersigned Examination Committee.

Prof. Ruy Monteiro Ribeiro

Advisor

Departamento de Economia - PUC-Rio

Prof. Diogo Abry Guillén

Departamento de Economia - PUC-Rio

Prof. Marco Antonio Cesar Bonomo

Departamento de Economia - Insper

Prof. Augusto Cesar Pinheiro da Silva

Vice Dean of Graduate Studies

Centro de Ciencias Sociais - PUC-Rio

Rio de Janeiro, April 9th, 2018 
All rights reserved.

Vitor Gabriel Rivas Martello

B.A., Economics, Insper, 2015

Bibliographic data

Martello, Vitor G R

Pre-FOMC Announcement Relief / Vitor Gabriel Rivas Martello; advisor: Prof. Ruy Monteiro Ribeiro. - Rio de janeiro: PUC-Rio, Departamento de Economia, 2018.

v., 51 f: il. color. ; $30 \mathrm{~cm}$

Dissertação (mestrado) - Pontifícia Universidade Católica do Rio de Janeiro, Departamento de Economia.

Inclui bibliografia

1. Economia - Teses. 2. Economia - Teses. 3. Anúncios Macroeconômicos;. 4. Prêmio de Risco em Ações;. 5. Incerteza de Mercado;. 6. Resolução de Incerteza;. 7. Alívio do Investidor;. I. Ribeiro, Ruy. II. Pontifícia Universidade Católica do Rio de Janeiro. Departamento de Economia. III. Título. 


\section{Acknowledgments}

If I were to write for those who helped me during my Master's degree course, I would probably forget most of them. However, I would like to thank all my family, for being supportive and understanding. Also, a special thanks to Júlia Rêgo, who was always by my side during this tough journey. I would also like to thank my advisor, Ruy Monteiro Ribeiro for all the opportunities and valuable contributions to this project. 


\section{Abstract}

Martello, Vitor G R; Ribeiro, Ruy (Advisor). Pre-FOMC Announcement Relief. Rio de Janeiro, 2018. 51p. Dissertação de mestrado - Departamento de Economia, Pontifícia Universidade Católica do Rio de Janeiro.

We show that the pre-FOMC announcement drift in equity returns occurs mostly in periods of high market uncertainty. Specifically, this abnormal return is explained by a significant reduction in the risk premium (implied volatility and variance risk premium) prior to the announcement, but only when the risk premium is high, e.g., when it is above its median. The relevant measures of market uncertainty are persistent and are not related to policy uncertainty or expectations. Markets do not become stressed in the days prior to the announcement, and the resolution of uncertainty is not reversed in the days after the meeting. Moreover, we explain why recent studies suggest that the pre-FOMC drift might have disappeared in the past decade, as this decline in the effect is due to time variation that was also present in older data. Additionally, CAPM only works on FOMC dates when the risk premium is high, e.g., implied volatility above its prior median level. The results are robust to different samples and to alternative risk premium and uncertainty measures.

\section{Keywords}

Macroeconomic Announcements; Equity Risk Premium; Market Uncertainty; Uncertainty Resolution; Investor Relief; 


\section{Resumo}

Martello, Vitor G R; Ribeiro, Ruy. Alívio Pré-Anúncio do FOMC. Rio de Janeiro, 2018. 51p. Dissertação de Mestrado Departamento de Economia, Pontifícia Universidade Católica do Rio de Janeiro.

Mostramos que o movimento do retorno de ações horas antes do anúncio do FOMC ocorre principalmente em períodos de alta incerteza de mercado. Especificamente, esse retorno anormal é explicado por uma redução significativa do prêmio de risco (volatilidade implícita e prêmio de variância) antes do anúncio, mas apenas quando o prêmio de risco do mercado é alto (quando está acima da sua mediana). As medidas de incerteza de mercado que são relevantes são persistentes e não são relacionadas à incerteza ou expectativa com relação à política. O mercado não fica estressado dias antes do anúncio, e a resolução de incerteza não é revertida dias após a reunião. Além disso, nós explicamos o porquê do movimento de antecipação não ser observado na última década, uma vez que a ausência de evidência advém da variação no tempo que também estava presente em dados passados. Adicionalmente, o CAPM funciona em datas de FOMC apenas quando o prêmio de risco é alto, ou seja, quando a volatilidade implícita está acima da mediana histórica até o momento. Os resultados são robustos a diferentes amostras e medidas alternativas de prêmio de risco e incerteza.

\section{Palavras-chave}

Anúncios Macroeconômicos; Prêmio de Risco em Ações; Incerteza de Mercado; Resolução de Incerteza; Alívio do Investidor; 


\section{Table of contents}

$\begin{array}{lll}1 & \text { Introduction } & 10\end{array}$

2 Data $\quad 14$

2.1 Monetary Policy Announcements 14

$\begin{array}{lll}2.2 & \text { Return and Volatility Measures } & 15\end{array}$

3 Empirical Results $\quad 17$

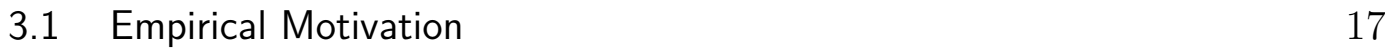

3.2 Conditional Analysis 20

3.2.1 FOMC Meetings during Stressed Periods and Investor Relief 20

3.2.2 Difference-in-Means Tests 24

3.2.3 Revisiting FOMC Meetings in Stressed vs Non-Stressed Periods 28

3.2.4 Uncertainty Resolution 30

$\begin{array}{ll}3.2 .5 & \text { Market Sell-Off }\end{array}$

3.3 Cross-Sectional Analysis 30

$4 \quad$ Robustness Analysis and Additional Controls $\quad 34$

4.1 Redefining Announcement Timing 34

4.2 All Scheduled Meetings at 2:15 pm 37

4.3 Adding Recent Data (Sep 2003 - Jan 2016) 39

4.4 Alternative Market Uncertainty Measures 41

5 Conclusions $\quad 44$

$\begin{array}{ll}\text { Bibliography } & 46\end{array}$

A Measures of Market Uncertainty, Policy Uncertainty and Policy Expectations 48

$\begin{array}{ll}\text { B FOMC Cycle } & 50\end{array}$ 


\section{List of figures}

Figure 3.1 Conditional Average of Excess Return and Uncertainty Realization

Figure 3.2 Average Intraday Patterns for Returns and Market Uncertainty for FOMC Meetings in Stressed and Non-Stressed Periods

Figure 3.3 Average Intraday Patterns for Returns and Market Uncertainty for FOMC Meetings in Stressed and Non-Stressed Periods

Figure 3.4 Market Uncertainty Pattern: 1-Month-Ahead Announcements

Figure 3.5 CAPM and Industry Portfolios: The Effect of Market Uncertainty

Figure A.1 Time Series of Market Uncertainty, Policy Uncertainty and Policy Expectations

Figure B.1 FOMC Cycle - Bi-weekly Pattern 


\section{List of tables}

Table 3.1 Descriptive Statistics - FOMC Announcements vs. Usual Days 18

Table 3.2 Difference-in-Means Test for Realized Equity Returns 25

Table 3.3 Difference-in-Means Test for Absolute Variation in VIX ${ }^{2} \quad 26$

Table 3.4 Accounting for Multiple Uncertainty Variables 27

Table 3.5 FOMC Meetings in Stressed vs Non-Stressed Periods and Interaction with Policy Direction 29

Table 3.6 Market Sell-Off before or after Announcement Window 31

Table 4.1 Robustness: Changing Announcement Timing and Adding Controls - Baseline Sample 36

Table 4.2 Robustness: Changing Sample and Adding Controls - (2) Sample 38

Table 4.3 Robustness: Changing Announcement Timing and Adding Controls - Extended Sample (2003-2016) 40

Table 4.4 Alternative Uncertainty Measures and Pre-FOMC Returns 42

Table 4.5 FOMC Returns and Relief with the Variance Risk Premium as Market Uncertainty

Table A.1 Correlation: Market Uncertainty, Policy Uncertainty and Policy Expectations 


\section{Introduction}

The interaction between macroeconomic conditions and stock market performance is a central question in finance. News about the economy or changes in policy should affect how investors discount future market cash flows. Hence, macroeconomic announcements are likely to impact market prices and volatility due both to the news they bring about future growth and their effect on uncertainty. Accordingly, (1) show that realized equity returns appear to be concentrated on days with macroeconomic announcements. Interestingly, (2) notes that such positive returns occur only a few hours before the announcement in the case of Federal Open Market Committee (FOMC) releases, terming this the pre-FOMC announcement drift. Other papers examine the price reaction after monetary policy announcements, e.g., (4) show evidence of a relief rally, with significant declines in the S\&P 500 Implied Volatility Index (VIX), after FOMC meetings accompanied by Summary of Economic Projections (SEP) releases. However, it remains a puzzle why there is pre-FOMC announcement drift and what determines its magnitude and timing.

Although our aim here is not to explain the reasons for the drift, we show that pre-announcement return drift is associated with significant declines in risk during times of high risk. Implied volatility and the variance risk premium decrease in the hours before the announcement in an almost perfect mirror image of the increase in market prices. Moreover, we show that the magnitude of the return drift and the decline in risk depends on the level of market implied volatility, or other related variables, days or even weeks prior to the announcement. Hereafter, we will refer to all these risk-related conditioning variables as market uncertainty, in contrast to policy uncertainty. We show that all effects associated with FOMC announcements become substantially clearer and significant when we condition on various measures of market uncertainty, but the same is not true when we consider policy uncertainty or expectations.

We show that the level of market uncertainty, proxied by implied volatility measured days before the pre-scheduled announcement or other related variables, is crucial to explain the magnitude of the return drift in the hours prior to the announcement. The average pre-FOMC drift when implied volatil- 
ity is above its prior median ${ }^{1}$ is 109 basis points (bps), while it is only 9.7 bps when it is below its median. In the bottom $20 \%$ of implied volatilities, the drift is close to zero or even negative, depending on the specification.

We also provide clear evidence of investor relief, i.e., a decline in implied volatility or other risk measures, hours before the announcement. The magnitude of this pre-announcement investor relief also depends on the level of market uncertainty. Considering the squared value of the VIX as our priced risk proxy, we show that, during high volatility periods, implied variance declines by 103.5 bps in anticipation of the announcement, while during low volatility periods, it rises by 0.3 bps. Hence, high volatility periods present both higher realized equity returns and greater resolution of market uncertainty hours before pre-scheduled announcements.

We also reject the idea that market uncertainty may increase in anticipation of FOMC meetings. Under this hypothesis, market participants would become increasingly concerned about the next meeting, leading to greater market uncertainty as the meeting approaches. The results would be similar when using a lag of few days or even a month, as the risk determinants of the drift are slow-moving and persistent. We find no evidence that relevant risk measures change systematically in the weeks preceding the announcement or in periods between FOMC meetings. Moreover, we find that the variation in the market uncertainty measure is not associated with the variation in the existing measures of policy and economic uncertainty.

One of our contributions is to show that the results become substantially clearer when we recognize that the pre-FOMC drift may not occur for all FOMC meetings and may not occur at all when markets are calm, independent of policy uncertainty. Here, we show that the time variation is substantial and that the effect is predictably very large in certain periods. Moreover, acknowledging its time variation allows us to obtain greater precision, as some of the effects now become statistically significant. Other papers have suggested that the announcement effect should vary over time but without necessarily providing supporting evidence. (1) present arguments, without supporting evidence, that market uncertainty should be a time-varying component of the above-average returns on announcement days. Moreover, (2) present results showing that market uncertainty, proxied by the VIX index, is one of the drivers of the heterogeneity in the pre-FOMC drift effect over time. In a related work, (4) show that stock market returns on broader set of announcements days are highly predictable, while returns for normal days are not predictable.

\footnotetext{
${ }^{1}$ To avoid look-ahead bias, we compute the median using only data prior to each event. Hence, this analysis provides out-of-sample results.
} 
Our analysis also provides explanations for other return patterns. (4), among others, note that during the last decade, no pre-announcement drift occurred. Here, we provide an argument that explains the absence of preannouncement drift, as investors faced low market volatility in the post-2010 sample. Moreover, the persistence of the anticipation movement presented by (2), i.e., the dependence of the current-meeting return on the past-eightmeeting returns, seems to be reflecting - and it is subsumed by - the slowmoving and persistent market uncertainty that we discuss here.

The literature that has thus far studied uncertainty resolution on such events restricts its analysis to the market reaction to the contents of meeting statements. (5) note that investors' risk appetite is the main driver of market returns after an announcement, as policy shocks trigger market movements through channels other than yields. (4) find evidence that announcements followed by the release of an SEP present higher post-announcement returns. They suggest that greater information flow leads to greater investor relief, which is translated into positive market performance. (6) argue that marketimplied volatility presents negative jumps, mostly on days with macroeconomic news. They also present empirical evidence that monetary policy announcements explain a substantial part of such sudden declines.

Interestingly, we also find that the CAPM only works on FOMC dates when implied volatility, or other related variables, is above its prior median. (1), (7) and (8) provide an extensive analysis of asset performance around scheduled announcements. Among other results, they document that on such days (i) the average stock market return is of a higher order of magnitude, and (ii) industry portfolios' market betas have a direct relationship with the industries' average daily returns, suggesting the validity of CAPM on announcement days. Here, we present evidence that this relationship does not hold in low-volatility periods and that CAPM with industry portfolios only works in periods of high market uncertainty.

In addition to the above-mentioned studies, our work is related to other papers that analyze asset price performance around pre-scheduled announcements. (9) and (10) characterize the response to policy surprises of market volatility and return, respectively. Although we do not control for any specific surprise measure, such that proposed by (11), the present work complements those studies because we do not solely consider the adjustment movement. (12) shows that the pre-FOMC announcement drift is part of a broadly bi-weekly pattern in market returns, as the market presents significant hikes during the even weeks, i.e., 0,2,4 and 6, of the FOMC cycle. We show that the returns observed at week 0 of the FOMC cycle actually depend on the level of mar- 
ket uncertainty observed days in advance. Moreover, this bi-weekly pattern in only present in stressed periods, as discussed in the Appendix. (13) provide evidence that the anticipation movement is not restricted to the stock market. They show that a dollar portfolio has positive returns hours before the announcement and that its magnitude depends on uncertainty over the policy decision. Here, we show that policy uncertainty is not relevant to explain stock market performance around pre-scheduled monetary policy announcements.

The remainder of this paper is organized as follows. Section 2 describes the data. Section 3 presents and discusses our empirical results, showing that the market uncertainty matters in explaining return, volatility and crosssectional behavior. Then, Section 4 provides results that confirm our findings' robustness to different samples, alternative measures and the inclusion of additional controls. Section 5 concludes the paper. 


\section{Data}

We analyze the intraday behavior of excess returns, implied volatility, realized volatility and the variance risk premium, as well as their patterns in the days and weeks around macroeconomic announcements. Specifically, we focus on US data and on market movements around pre-scheduled FOMC announcements. Here, we describe the data used in our analysis.

\section{1}

\section{Monetary Policy Announcements}

The FOMC is the body responsible for open market operations within the Federal Reserve. The committee holds eight regularly scheduled meetings every year, during which the board discusses current economic conditions and future economic scenarios and determines the appropriate monetary policy stance. Since 1994, the committee has released its official statement to the public immediately after the meeting. ${ }^{1}$

Our baseline sample ranges from September 22, 2003, to March 31, 2011, due to limited data availability before 2003 and because, after March 2011, announcements no longer took place around 2:15 pm. More precisely, we do not have access to intraday VIX before September 2003, hence the beginning of the sample. As robustness checks, we also present results for the the same sample period used in (2), focusing exclusively on intraday returns and not on intraday market uncertainty measures. We also extend the analysis to 2016, but here we use the actual time of the release and not a pre-specified timing.

Our baseline sample period covers 1893 business days, 65 of which coincide with FOMC meeting days. However, we rely only on 60 days associated with pre-scheduled meetings, from which statements were released around 2:15 pm. ${ }^{2}$ This sample allows us to decompose the total market movement on these days into two components: the anticipation component, which occurs before the

\footnotetext{
${ }^{1}$ Before 1994, market participants did not gain access to the actual monetary policy decision and could only infer it from actual actions, e.g., open market interventions by the monetary authority on the first day following the meeting.

${ }^{2}$ Non-scheduled meetings were not considered, as investors could not anticipate the Fed's interventions. Two such meetings were held in 2007, and the other three took place in 2008.
} 
actual statement, and the adjustment component, which measures the market reaction following the announcement.

Throughout our sample, the blackout period was in force, implying that investors did not receive any information from the monetary policy committee during the five days preceding pre-scheduled meetings.

\section{2}

\section{Return and Volatility Measures}

To compute the market excess return, we consider the S\&P 500 total return over the 1-month Treasury yield. By exploring high-frequency data, we are able to compute intraday returns, such as five-minute returns, and intraday volatility of returns. We compute cumulative excess returns over different time windows, such as close-to-close, open-to-close and mid-to-mid returns (i.e., 2pm-to-2pm returns), for example, allowing us to measure the anticipation and adjustment movements. The same was done with intraday $V I X^{2}$ variations.

Our focus is on measures of market uncertainty that appear to be closely connected to the market risk premium. We consider both implied volatility and the variance risk premium as measures of the equity risk premium, consistent with (14) and (15), respectively. (14) suggests that the equity premium has a lower bound given by $R_{f} * S V I X^{2}$, where SVIX is his proposed measure of the implied volatility of a simple variance swap contract. Here, we use intraday and daily data on $V I X^{2}$ as one of our high-frequency measures of uncertainty based on his claim that the difference between $V I X$ and $S V I X$ is very often too small to matter. We also use this information to compute the variance risk premium.

As market uncertainty measures, we consider four different proxies: (i) the squared value of the Implied Volatility Index (VIX $X^{2}$ hereafter), (ii) the daily realized variance of market returns ( $R V$ ar, hereafter), (iii) the equity premium lower bound proposed by (14) (ERP, hereafter), and (iv) the variance risk premium, as measured by (15). The daily realized variance of market returns is computed using the sum of squared market returns over the past month. We also consider realized measures based on intraday returns in particular cases. These market uncertainty measures are highly correlated with one another and typically present positive spikes with bad news flows and sudden drops as market uncertainty is resolved, as suggested by (6). ${ }^{3}$ Additional information on the time series of our state variables is reported in the Appendix.

${ }^{3}(16)$ and (17) explore the dependency of market returns on monetary policy shocks using variables highly correlated with our market uncertainty measures. Nevertheless, their analyses focus only on the adjustment component and consider the market response to monetary policy shocks from (11). 
The Economic Policy Uncertainty Index (EPU) proposed by (18) is our baseline proxy for policy uncertainty. The index reflects the frequency of articles in the top-ten newspapers that contain specific combinations of terms associated with uncertainty, the economic situation and regulation/intervention. Another proxy that we consider is the 10-year Treasury yield Implied Volatility Index $(T Y V I X)$. This implied volatility measures the uncertainty regarding future treasury yields. Hence, it is an alternative measure of uncertainty over the monetary policy decision. ${ }^{4}$ The third potential driver considered here is the market expectation of the future policy decision. We use a straightforward approach to recover this expectation, based on the difference between the 1-year Treasury yield and the 1-month Treasury yield - the term slope (Slope).

${ }^{4}$ The 30-year Implied Volatility Index (TIV) dynamics are considered in (13) as a conditioning variable when analyzing currency returns. The market's reaction to policy shocks (post-announcement movement) depends on the TIV level before the meeting. 


\section{3 \\ Empirical Results}

In this section, we present the empirical findings of our conditional analysis. We analyze the statistical significance of our results using continuous measures of market uncertainty as conditioning variable, but we also consider versions in which we discretize our conditioning variables into two states (high and low uncertainty). In this section, we also provide evidence that is inconsistent with the idea that our market uncertainty measures may be moving in anticipation of FOMC meetings, implying a sell-off in the days and weeks prior to the announcement or a reversion in the post-announcement period. To conclude this section, we test the performance of the CAPM model on high-volatility and low-volatility FOMC days. In this section, our baseline proxies are $V I X^{2}$ (market uncertainty), the EPU Index (policy uncertainty) and the term slope (policy expectation). The consideration of different proxies is relegated to the robustness checks in Section 4. We begin with a simple exercise to motivate our analysis.

\section{1}

\section{Empirical Motivation}

As seen in Table 3.1, days with scheduled monetary policy announcements present higher average returns - consistent with (1) - and greater uncertainty resolution - as in (6). Moreover, the average realized equity return is greater in the 24 hours preceding an announcement, consistent with (2). The novel fact in this table is that reduction in implied volatility is also higher in the 24 hours preceding a meeting, suggesting that uncertainty was resolved before the announcement.

The motivation for our analysis of a time-varying effect is that the risk premium demanded by investors around pre-scheduled meetings may be affected by the state of the economy and is not necessarily associated with policy uncertainty perse. Periods with high (low) market uncertainty or volatility, for example, may be associated with periods of a high (low) equity premium delivered for those who bear risk. Although, as noted by (2), most of the equity premium on such days is observed hours before the announcement, it may be the case that its magnitude is somehow associated with market 
Table 3.1: Descriptive Statistics - FOMC Announcements vs. Usual Days

\begin{tabular}{|c|c|c|c|c|c|c|c|c|c|c|}
\hline \multirow[b]{2}{*}{ SPX-Rf (\%) } & \multicolumn{5}{|c|}{ FOMC Ann Days } & \multicolumn{5}{|c|}{ Usual Days } \\
\hline & Average & StdDev & Median & Skew & Kurtosis & Average & StdDev & Median & Skew & Kurtosis \\
\hline $\mathrm{C}(\mathrm{t}-1)-\mathrm{C}(\mathrm{t})$ & 0.48 & 1.34 & 0.35 & 1.11 & 1.92 & 0.00 & 1.36 & 0.08 & -0.43 & 11.85 \\
\hline $2(\mathrm{t}-1)-2(\mathrm{t})$ & 0.57 & 1.60 & 0.26 & 3.52 & 18.26 & -0.01 & 1.29 & 0.04 & 0.14 & 24.85 \\
\hline $\mathrm{O}(\mathrm{t}-1)-2(\mathrm{t})$ & 0.53 & 1.59 & 0.34 & 2.15 & 9.41 & -0.04 & 1.53 & 0.07 & -0.72 & 13.98 \\
\hline $2: 20(\mathrm{t})-\mathrm{C}(\mathrm{t})$ & 0.02 & 0.96 & 0.06 & 0.61 & 1.55 & 0.02 & 0.71 & 0.02 & 1.28 & 24.01 \\
\hline $\begin{array}{l}2(\mathrm{t})-3(\mathrm{t}) \\
\Delta V I X^{2} \text { (p.p.) }\end{array}$ & 0.22 & 0.74 & 0.20 & 0.72 & 3.01 & 0.01 & 0.37 & 0.01 & 0.60 & 12.49 \\
\hline $\mathrm{C}(\mathrm{t}-1)-\mathrm{C}(\mathrm{t})$ & -0.28 & 1.47 & -0.13 & 0.23 & 13.54 & 0.03 & 1.78 & -0.03 & 0.75 & 47.61 \\
\hline $2(\mathrm{t}-1)-2(\mathrm{t})$ & -0.38 & 1.56 & -0.11 & -4.84 & 28.99 & 0.02 & 1.69 & -0.02 & 1.47 & 82.68 \\
\hline $\mathrm{O}(\mathrm{t}-1)-2(\mathrm{t})$ & -0.46 & 1.37 & -0.11 & -2.73 & 9.23 & -0.03 & 2.00 & -0.04 & 0.98 & 69.09 \\
\hline $2: 20(\mathrm{t})-\mathrm{C}(\mathrm{t})$ & -0.11 & 0.73 & -0.03 & -3.20 & 17.37 & -0.01 & 0.96 & -0.01 & -2.87 & 89.52 \\
\hline $2(\mathrm{t})-3(\mathrm{t})$ & -0.21 & 0.44 & -0.07 & -1.50 & 2.79 & 0.00 & 0.44 & 0.00 & 1.67 & 56.03 \\
\hline
\end{tabular}

uncertainty or volatility preceding the announcement.

We provide a simple result to motivate our conditional analysis, both of realized equity returns and the resolution of market uncertainty. Figure 3.1 shows that the average realized equity return and the average reduction in a particular market uncertainty measure are monotonically associated with the market uncertainty level prior to the announcement. Hence, greater market uncertainty is associated with higher compensation for risk and greater uncertainty resolution hours before the announcement.

Each black (grey) bar in Figure 3.1 reports the average pre-announcement return (VIX $X^{2}$ variation) in a specific sub-sample, selected according to quantiles of the chosen state variable distribution. For each announcement, we collect the level of the state variable six days before the announcement (i.e., the last day outside the blackout period). If the observed level is within the respective quantile of the state variable distribution, the announcement is considered in the computation of the average. For example, in the $100 \%$ bar, the full sample is used, while in the $80 \%+(-)$ bar, we consider the events associated with the top (bottom) $80 \%$ of the 6 -day-lagged state variable distribution. To control for interactions between the three state variables, the figure on the bottom is generated using the distribution of the market uncertainty that is orthogonal to the other two measures (policy uncertainty and policy expectations), which is recovered by using the residuals of multivariate OLS regressions of the respective measure on the other two measures. The relationship appear to be monotonic for market uncertainty, while similar figures for the other two state variables, not reported here, present a relatively high equity premium in both tails of the distribution. 
Figure 3.1: Conditional Average of Excess Return and Uncertainty Realization

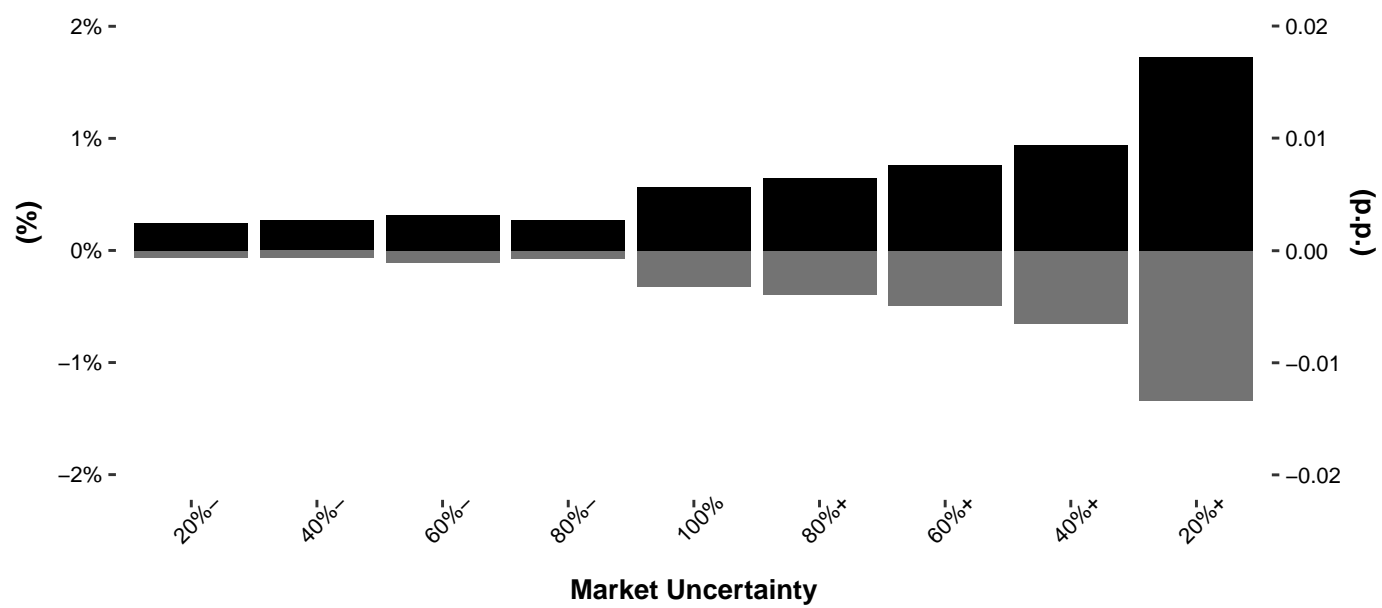

Market Uncertainty

$2 \%-$

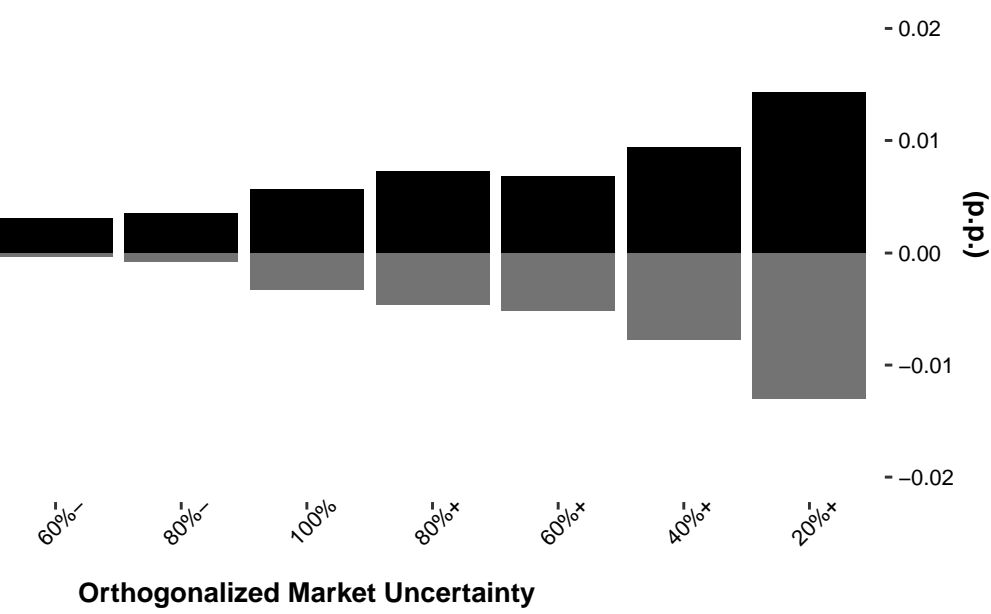

Notes: This figure reports the average excess returns (black bars, left y-axis) and uncertainty resolution (gray bars, right y-axis) observed twenty-four hours before pre-scheduled monetary policy announcements. The S\&P 500 return over the 1-month Treasury yield is used as our excess return measure, while uncertainty resolution is measured by the variation in $V I X^{2}$. The averages in each graph are computed using different samples, selected according to the distribution of market uncertainty, which is observed six days before the announcement day. The full sample average is represented by the $100 \%$ bar, while X\%+ (-) represents the case in which only the excess returns associated with the top (bottom) X\% level of the chosen state variable's distribution are used to compute the reported average returns. Market uncertainty is proxied by $V I X^{2}$. In the second graph, the orthogonalized state variable is used. The orthogonalized version is the residual of the OLS regression of market uncertainty on policy uncertainty and expectations. All variables were normalized before running the OLS regression. The sample period ranges from September 25, 2003, to March 31, 2011. 


\section{2 \\ Conditional Analysis}

\subsection{1}

\section{FOMC Meetings during Stressed Periods and Investor Relief}

Figure 3.2 shows that the pre-FOMC announcement drift on equity prices appears only during periods of high market uncertainty (henceforth, stressed periods) but are independent of policy uncertainty and policy expectations. We say that an announcement occurred in a stressed period whenever the chosen market uncertainty variable is greater than its historical median up to that day, when measured six days before the meeting (before the blackout period). The upper graph of Figure 3.2 depicts the cumulative S\&P 500 excess return around the announcement, including the twenty-four hours before and after the release. The red line and shaded area represent the average trajectory of the cumulative realized return and its 95\% confidence band on stressed windows, respectively. The windows are centered at $2: 15 \mathrm{pm}$, the relevant time for this particular sample.

This decomposition suggests that the puzzle highlighted by (2) actually occurs only for FOMC meetings during stressed periods. In stressed periods, the average cumulative excess return reaches 128 bps within the twentyfour hours prior to the pre-scheduled announcement. This magnitude is more than twice the size of the cumulative excess return that is achieved without decomposing the days into stressed and non-stressed days, as the gray line reaches a level of approximately $55 \mathrm{bps}$ in the same window.

For comparison, the black solid line reports the average trajectory of windows without monetary policy announcements. The shaded areas with the corresponding color represent the 95\% confidence bands, and they suggest that the red and black trajectories are statistically significantly different. In the following subsections, this difference will be formally tested using various regression specifications. Although the average trajectory during meetings in non-stressed periods is slightly positive (green line), its movement is not significantly different from that in non-announcement-day windows.

Moreover, the second graph in Figure 3.2 provides evidence that the $V I X^{2}$ level presents a declining trend in the hours before the announcements during stressed periods, aligned with the upward movement of the cumulative realized equity return. Markets seem to behave as if uncertainty were being resolved even before the statement actually goes to the press, consistent with the view of investor relief prior to the announcement. The reduction in $V I X^{2}$ in the hours before announcements during stressed periods reaches approximately 
Figure 3.2: Average Intraday Patterns for Returns and Market Uncertainty for FOMC Meetings in Stressed and Non-Stressed Periods

3 -
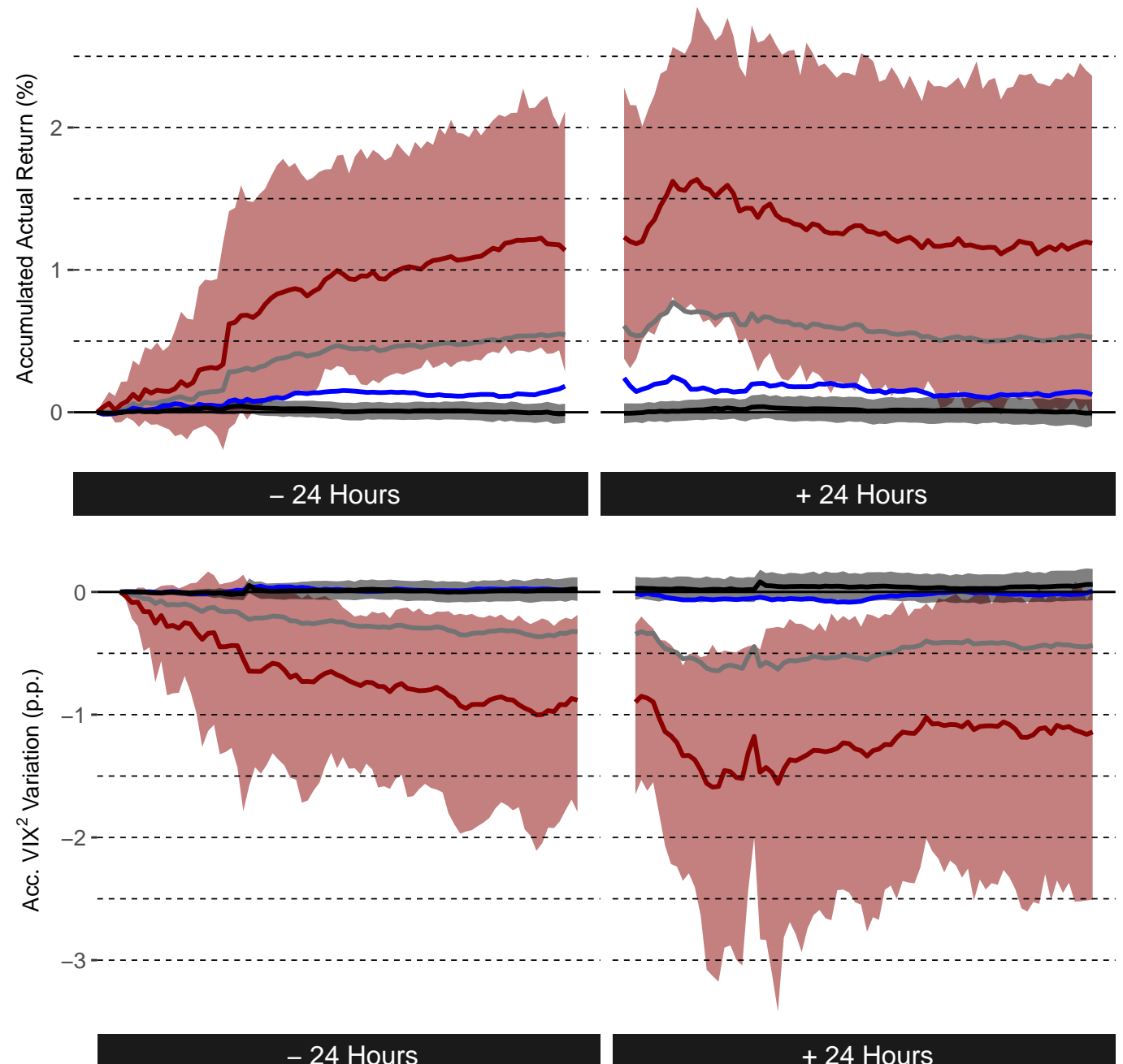

Notes: The graph presents the cumulative S\&P 500 excess return and absolute variation of $V I X^{2}$ both twenty four-hours prior to and after the pre-scheduled announcement. The 48-hour window is centered on 2:15 pm. Two types of windows are considered here: (i) windows centered on pre-scheduled meetings that took place in stressed periods and (ii) "usual windows" without any pre-scheduled meeting. Stressed meetings are those that occurred six days after observing a market uncertainty - proxied by orthogonalized $V I X^{2}$ to both policy uncertainty and expectations - level greater than its median up to that day. "Usual windows" do not overlap with one another and are outside weeks of monetary policy announcements. The red and dark gray lines represent the average trajectory of cases (i) and (ii), respectively. The shaded area with the corresponding color reports the $95 \%$ confidence bands for the trajectories. The gray line reports the average trajectory around pre-scheduled FOMC meetings without decomposition (all meetings, as in (2)) and the blue line represents the average trajectory around announcements that took place in non-stressed periods. The sample period considered here ranges from September 25, 2003, to March 31, 2011. 
Figure 3.3: Average Intraday Patterns for Returns and Market Uncertainty for FOMC Meetings in Stressed and Non-Stressed Periods
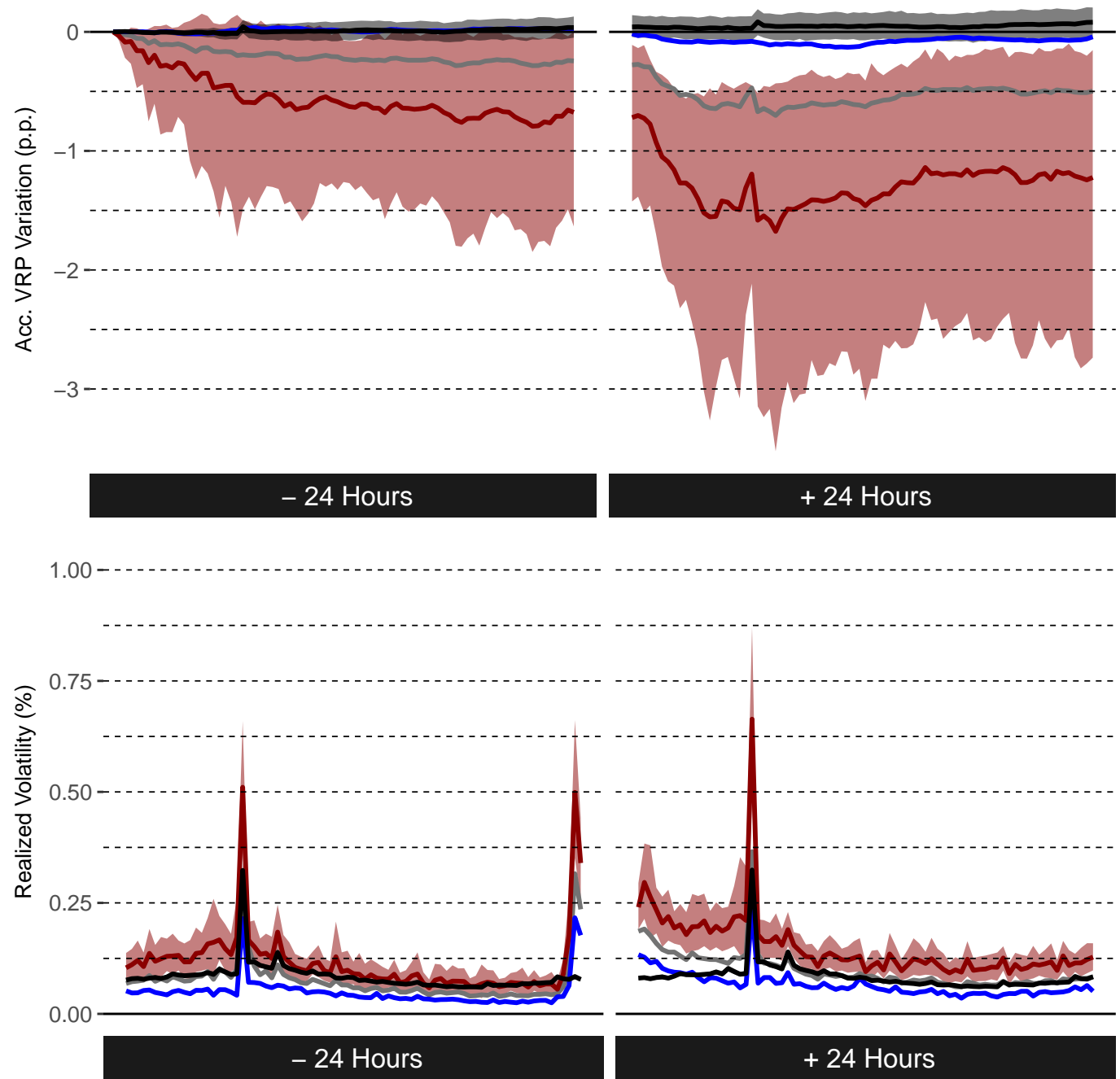

Notes: The graph presents the absolute cumulative variation of the variance risk premium ( $V R P$, computed as in (15)), and realized volatility (standard deviation of minute-by-minute returns) both twenty four-hours prior to and after the pre-scheduled announcement. The 48-hour window is centered on 2:15 pm. Two types of windows are considered here: (i) windows centered on pre-scheduled meetings that took place in stressed periods and (ii) "usual windows" without any pre-scheduled meeting. Stressed meetings are those that occurred six days after observing a market uncertainty - proxied by orthogonalized VIX ${ }^{2}$ to both policy uncertainty and expectations - level greater than its median up to that day. "Usual windows" do not overlap with one another and are outside weeks of monetary policy announcements. The red and dark gray lines represent the average trajectory of cases (i) and (ii), respectively. The shaded area with the corresponding color reports the $95 \%$ confidence bands for the trajectories. The gray line reports the average trajectory around pre-scheduled FOMC meetings without decomposition (all meetings, as in (2)), and the blue line represents the average trajectory around announcements that took place in non-stressed periods. The sample period considered here ranges from September 25, 2003, to March 31, 2011. 
Figure 3.4: Market Uncertainty Pattern: 1-Month-Ahead Announcements

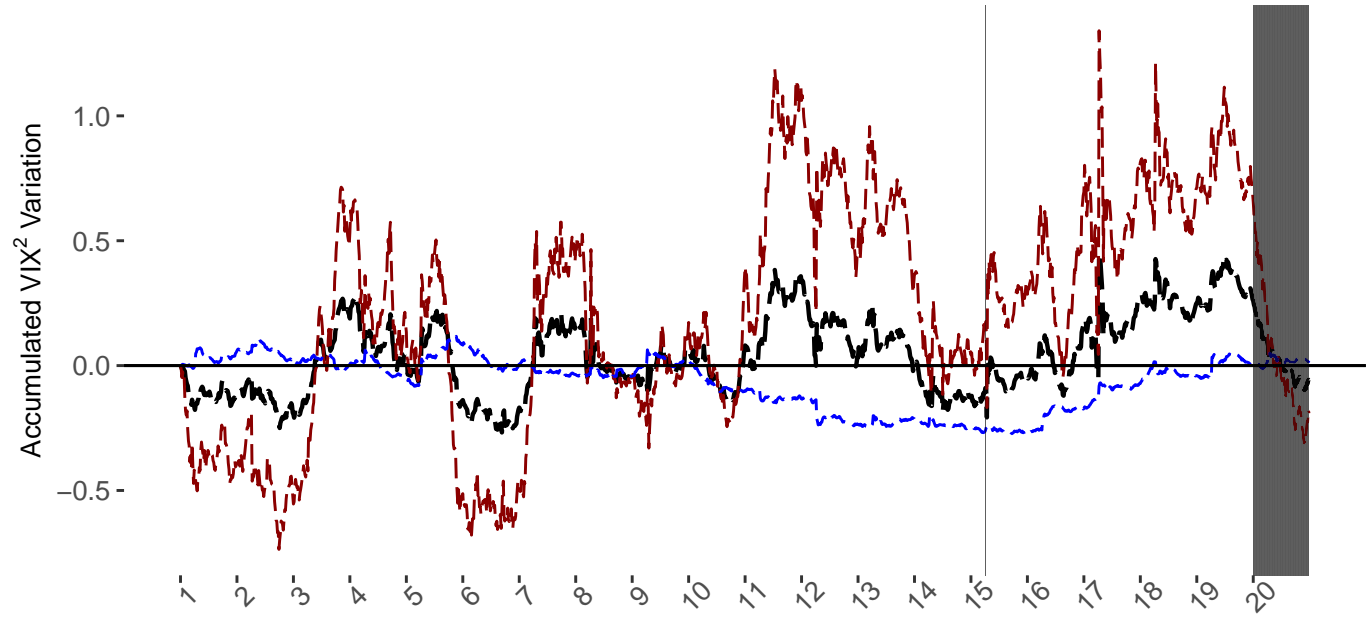

20-Days before the Announcement Release

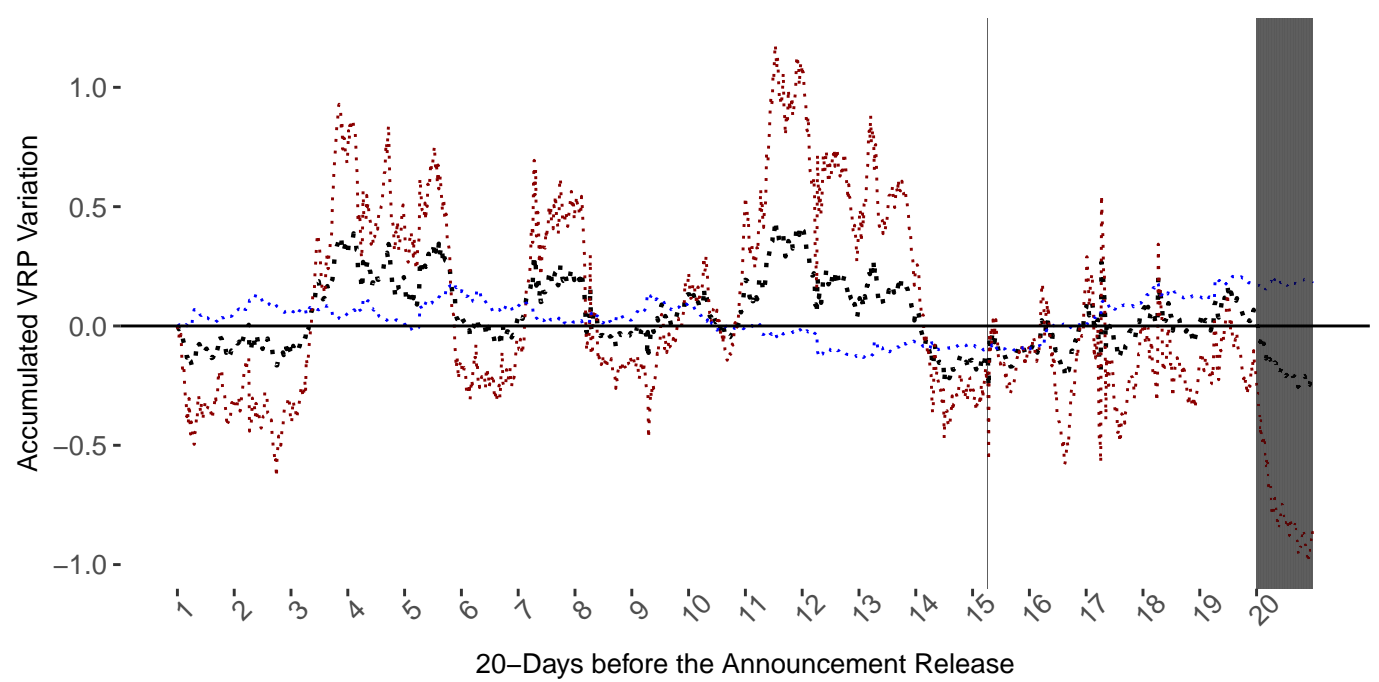

Notes: The graph presents the absolute variation of $V I X^{2}$ (upper graph) and the variance risk premium (as proposed by (15) - bottom graph) during the 20-days preceding the announcement time. The average trajectories are computed considering (i) all announcements (black dashed line), (ii) only announcements that took place during stressed periods (red dashed line) and (iii) only announcements that took place in non-stressed periods (blue dashed line). Stressed meetings are those that occurred six days after observing a market uncertainty - proxied by $V I X^{2}$ orthogonal to policy uncertainty and expectations - level greater than its median up to that day. The shaded gray area represents the 24 hours preceding the announcement. The vertical gray line represents the beginning of the blackout period. 
$1 \%$ immediately before the announcement, and this movement is at least twice the size of that when we count all announcements. Note that immediately after the announcement, there is a sudden decline in the $V I X^{2}$ level, supporting the empirical evidence of negative jumps after announcements, as discussed by (6).

\section{2 .2}

\section{Difference-in-Means Tests}

We now focus on difference-in-means tests in which we test whether market uncertainty can explain the variation in the pre-FOMC drift or other patterns surrounding an announcement. To do so, we run regressions considering various specifications as described below:

$$
Y_{t}^{j}=\alpha+\beta_{1} * Z_{t-6}+\beta_{2} * D_{[t=F O M C]}+\beta_{3} * Z_{t-6} * D_{[t=F O M C]}+\epsilon
$$

where $Y_{t}^{j}$ represents the cumulative realized market excess return or the cumulative variation in $V I X^{2}$ over the $j$ window around day $t, D$ is a dummy variable that takes value 1 when a pre-scheduled monetary policy statement takes place on day $t$, and $Z_{t-6}$ is our choice of market uncertainty variable from the set of state variables. We lag our state variables by six days, as any information received by investors during the blackout period does not come from policy makers, and is treated here as noise. Moreover, we want to avoid the impact of any sell-off prior to the meeting, a possibility that we also rule out below. Nevertheless, the results are similar for a one-day or longer lags. Thus, investors' entire information set is known at the closing time immediately before the blackout period, $t-6$. Five specifications for $j$ are reported here: (i) Close(t-1)-Close(t), (ii) Close(t-1)-2pm(t), (iii) Open(t-1)$2 \mathrm{pm}(\mathrm{t})$, (iv) 2:20pm(t)-Close(t) and (v) $2 \mathrm{pm}(\mathrm{t}): 3 \mathrm{pm}(\mathrm{t})$.

Table 3.2 presents evidence that the magnitude of the pre-announcement drift does depend on the level of market uncertainty, measured six days before the meeting. Table 3.2 reports estimates of Equation (3-1) with the realized equity return as the dependent variable. As seen in all panels, the realized market returns on pre-scheduled FOMC announcement days are, on average, higher than those on other days, as previously documented by (1) and (2). However, when the level of market uncertainty is one standard deviation above its mean, the average increases by 109.4 bps We do not find evidence of a post-announcement movement, suggesting that the overall daily movement reflects only the anticipation movement. Panels B and C, which are based on policy uncertainty and expectation measures, are clearly different, as the only statistically significant effect comes from the calendar component (i.e., the FOMC dummy). Hence, these regressions do not reject the hypothesis that 
neither policy uncertainty nor policy expectations can explain market returns on such days.

Table 3.2: Difference-in-Means Test for Realized Equity Returns

\begin{tabular}{|c|c|c|c|c|c|}
\hline Dep. Var. & & S\&P 50 & Excess Retr & $\mathrm{m}(\mathrm{t}: \mathrm{T})$ & \\
\hline $\mathrm{t}: \mathrm{T}=$ & $\mathrm{C}(\mathrm{t}-1)-\mathrm{C}(\mathrm{t})$ & $2(\mathrm{t}-1)-2(\mathrm{t})$ & $\mathrm{O}(\mathrm{t}-1)-2(\mathrm{t})$ & $2: 20(\mathrm{t})-\mathrm{C}(\mathrm{t})$ & $2(\mathrm{t})-3(\mathrm{t})$ \\
\hline & Pan & A: Market & Uncertainty & & \\
\hline Ann. Day & $0.471^{* * *}$ & $0.548^{* * *}$ & $0.529^{* * *}$ & -0.006 & $0.212^{* *}$ \\
\hline & {$[0.162]$} & {$[0.131]$} & {$[0.154]$} & {$[0.121]$} & {$[0.092]$} \\
\hline$\&$ Market Unc. & 0.390 & $1.094^{* * *}$ & $0.954^{* * *}$ & -0.018 & 0.075 \\
\hline & {$[0.371]$} & [0.303] & {$[0.323]$} & {$[0.252]$} & {$[0.146]$} \\
\hline$R^{2}$ & $0.58 \%$ & $3.51 \%$ & $1.95 \%$ & $0.98 \%$ & $2.05 \%$ \\
\hline & $\mathrm{Par}$ & B: Policy & Jncertainty & & \\
\hline Ann. Day & $0.478^{* * *}$ & $0.569 * * *$ & $0.546^{* * *}$ & -0.004 & $0.213^{* *}$ \\
\hline & {$[0.170]$} & {$[0.187]$} & {$[0.190]$} & {$[0.123]$} & [0.091] \\
\hline$\&$ Policy Unc. & 0.306 & 0.660 & 0.613 & -0.015 & 0.171 \\
\hline & {$[0.243]$} & {$[0.430]$} & {$[0.374]$} & {$[0.178]$} & [0.139] \\
\hline$R^{2}$ & $0.39 \%$ & $1.32 \%$ & $0.8 \%$ & $0.51 \%$ & $2.22 \%$ \\
\hline & Par & l C: Policy & xpectation & & \\
\hline Ann. Day & $0.479^{* * *}$ & $0.572^{* * *}$ & $0.550^{* * *}$ & -0.005 & $0.213^{* *}$ \\
\hline & {$[0.174]$} & {$[0.206]$} & {$[0.206]$} & {$[0.123]$} & [0.094] \\
\hline$\& 5$ Policy Exp. & -0.043 & 0.020 & 0.023 & -0.012 & -0.054 \\
\hline & {$[0.242]$} & {$[0.213]$} & {$[0.210]$} & {$[0.159]$} & [0.147] \\
\hline$R^{2}$ & $0.25 \%$ & $0.49 \%$ & $0.27 \%$ & $-0.15 \%$ & $0.84 \%$ \\
\hline
\end{tabular}

Notes: This table reports estimated coefficients for Equation (3-1) with the realized equity return as the dependent variable. Standard errors are computed using the White estimator. The constant term and the state variable by itself (without interaction) are omitted. Ann. Day is a dummy that takes value 1 when $t$ is a pre-scheduled announcement day. Panel A reports the results with market uncertainty, proxied by the $V I X^{2}$. Panel B reports the results with policy uncertainty, proxied by the EPU Index. Panel C reports the results with policy expectations, the difference between 1-year and 1-month Treasury yields. The three state variables are standardized. The table reports the adjusted $R^{2}{ }^{*}, * *$, and *** indicate significance at 10,5 , and $1 \%$, respectively. The sample is daily and ranges from September 22, 2003, to March 31, 2011.

Moreover, Table 3.3 shows that days with higher market uncertainty prior to an announcement lead to more significant resolution of this uncertainty in the hours before the announcement. Table 3.3 presents the estimates of Equation 3-1 using one of our market uncertainty realization proxies - variation in $V I X^{2}$ - as the dependent variable. As suggested by (6), sudden declines - or negative jumps - in market uncertainty usually follow policy announcements. Table 3.3 also suggests that the jump is even higher when market uncertainty is higher and/or policy uncertainty is higher, as results using the $2 \mathrm{pm}(\mathrm{t}): 3 \mathrm{pm}(\mathrm{t})$ window suggest. However, policy uncertainty and policy expectations have nothing to do with the early resolution of uncertainty observed before the announcement.

However, market uncertainty, policy uncertainty and policy expectations are not orthogonal to one another. Market uncertainty may be higher because policy uncertainty is also at a higher level. To address this concern, Table 3.4 presents estimates of Equation (3-1) simultaneously using two state variables, but now we consider the residual of the projection of market uncertainty on 
Table 3.3: Difference-in-Means Test for Absolute Variation in VIX ${ }^{2}$

\begin{tabular}{|c|c|c|c|c|c|}
\hline \multirow{2}{*}{$\begin{array}{l}\text { Dep. Var. } \\
\mathrm{t}: T=\end{array}$} & \multicolumn{5}{|c|}{ Absolute Variation of $V I X^{2}(\mathrm{t}: \mathrm{T})$} \\
\hline & $\mathrm{C}(\mathrm{t}-1)-\mathrm{C}(\mathrm{t})$ & $2(\mathrm{t}-1)-2(\mathrm{t})$ & $\mathrm{O}(\mathrm{t}-1)-2(\mathrm{t})$ & $2: 20(\mathrm{t})-\mathrm{C}(\mathrm{t})$ & $2(\mathrm{t})-3(\mathrm{t})$ \\
\hline \multicolumn{6}{|c|}{ Panel A: Market Uncertainty } \\
\hline \multirow[t]{2}{*}{ Ann. Day } & -0.292 & $-0.371^{* * *}$ & $-0.389 * * *$ & -0.092 & $-0.206^{* * *}$ \\
\hline & {$[0.179]$} & {$[0.120]$} & {$[0.129]$} & {$[0.090]$} & {$[0.049]$} \\
\hline \multirow[t]{2}{*}{$\&$ Market Unc. } & 0.121 & $-1.055^{* * *}$ & -0.651 & -0.006 & $-0.186^{* * *}$ \\
\hline & {$[0.671]$} & {$[0.362]$} & {$[0.302]$} & {$[0.296]$} & {$[0.075]$} \\
\hline$R^{2}$ & $-0.02 \%$ & $1.87 \%$ & $1.60 \%$ & $0.88 \%$ & $1.18 \%$ \\
\hline \multicolumn{6}{|c|}{ Panel B: Policy Uncertainty } \\
\hline \multirow[t]{2}{*}{ Ann. Day } & -0.290 & $-0.391^{* *}$ & $-0.405^{* * *}$ & -0.094 & $-0.209^{* * *}$ \\
\hline & {$[0.189]$} & [0.182] & {$[0.164]$} & {$[0.095]$} & {$[0.050]$} \\
\hline \multirow[t]{2}{*}{$\&$ Policy Unc. } & 0.064 & -0.662 & -0.434 & -0.014 & $-0.197 * * *$ \\
\hline & {$[0.463]$} & [0.467] & [0.334] & [0.197] & {$[0.061]$} \\
\hline$R^{2}$ & $-0.04 \%$ & $0.54 \%$ & $0.55 \%$ & $0.34 \%$ & $1.17 \%$ \\
\hline \multicolumn{6}{|c|}{ Panel C: Policy Expectation } \\
\hline \multirow[t]{2}{*}{ Ann. Day } & -0.289 & $-0.395^{*}$ & $-0.407^{*}$ & -0.093 & $-0.209^{* * *}$ \\
\hline & {$[0.190]$} & {$[0.203]$} & {$[0.181]$} & {$[0.096]$} & {$[0.054]$} \\
\hline \multirow[t]{2}{*}{83 Policy Exp. } & 0.240 & -0.076 & -0.009 & 0.049 & 0.131 \\
\hline & {$[0.216]$} & {$[0.220]$} & {$[0.224]$} & {$[0.113]$} & {$[0.095]$} \\
\hline$R^{2}$ & $0.01 \%$ & $0.03 \%$ & $0.01 \%$ & $-0.12 \%$ & $0.75 \%$ \\
\hline
\end{tabular}

Notes: This table reports estimated coefficients for Equation (3-1) with the absolute variation of $V I X^{2}$ as the dependent variable. Standard errors are computed using the White estimator. The constant term and the state variable by itself (without interaction) are omitted. Ann. Day is a dummy that takes value 1 when $t$ is a pre-scheduled announcement day. Panel A reports the results with market uncertainty, proxied by the $V I X^{2}$. Panel B reports the results with policy uncertainty, proxied by the EPU Index. Panel $\mathrm{C}$ reports the results with policy expectations, the difference between 1-year and 1-month Treasury yields. The three state variables are standardized. The table reports the adjusted $R^{2} .{ }^{*},{ }^{* *}$, and ${ }^{* * *}$ indicate significance at 10,5 , and $1 \%$, respectively. The sample is daily and ranges from September 22, 2003, to March 31, 2011.

policy uncertainty or policy expectations in Panels A and B, respectively.

Table 3.4 is consistent with the view that market uncertainty is the main driver of the magnitude of the equity premium and the realization of uncertainty hours prior to an announcement. Orthogonal market uncertainty remains statistically significant in both panels and continues to explain the difference in the means of cumulative excess returns hours before the announcement. The realized equity return in the twenty-four hours prior to the announcement is 139.5 bps higher if market uncertainty (orthogonal to policy uncertainty) is one standard deviation above its mean. If we consider the market uncertainty that is orthogonal to policy expectations, we find that the results are basically unaltered from those presented in Tables 3.2 and 3.3, where we considered market uncertainty without any orthogonalization. 


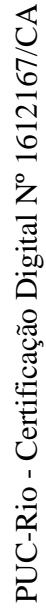

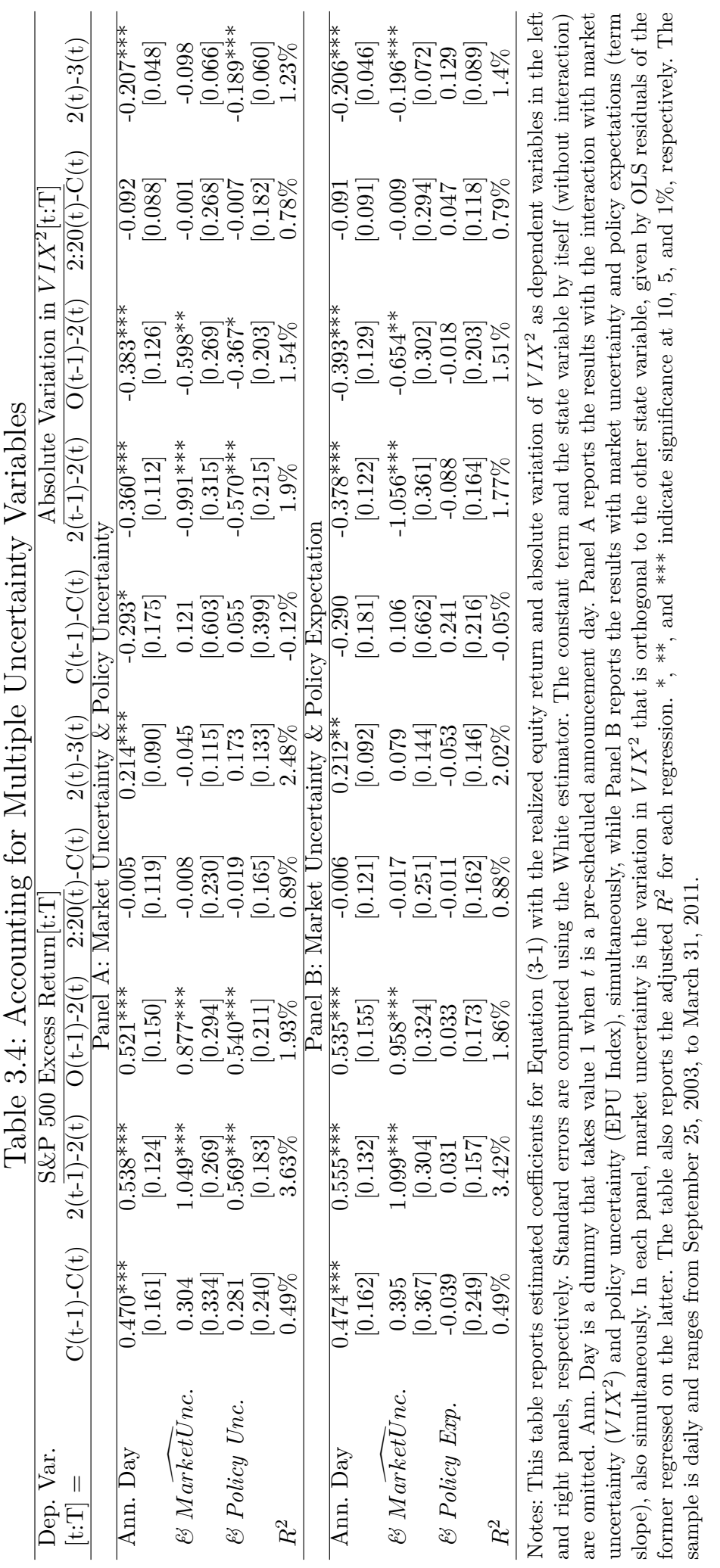


Moreover, VIX ${ }^{2}$ declines, on average, by 0.991 p.p. when the market uncertainty that is orthogonal to policy uncertainty is one standard deviation above its mean. Again, the results obtained using market uncertainty that is orthogonal to policy expectations seem to be unchanged relative to the main case.

In all cases, equity premium realization and uncertainty resolution are aligned, implying that the pre-FOMC drift is accompanied by pre-FOMC investor relief.

\subsection{3}

\section{Revisiting FOMC Meetings in Stressed vs Non-Stressed Periods}

In this subsection, we again decompose the announcement days into those that occurred during stressed periods and those that took place during nonstressed periods, as we did to construct Figure 3.2, but now we use regressionbased tests. As all our market uncertainty measures present spikes, it may be useful to consider a non-linear case in which we simply divide the conditioning variable into discrete states. By doing so, we also avoid the impact of outliers. We implement a simple decomposition into two states: high and low market uncertainty. Henceforth, market uncertainty is always orthogonal to policy uncertainty and expectations. We always use the median value of market uncertainty in the dates prior to any announcement to define the threshold between stressed and non-stressed states. We use the sample from 1994 up to the referred date (i.e., rolling sample) when computing the median to avoid noisy selection of states in the beginning of the sample. Hence, we use the following definitions for our dummies:

$$
D_{\text {stressedFOMC }}= \begin{cases}1, & \text { if } t=F O M C \text { and } \widehat{V I X}_{t-6}^{2} \geq \operatorname{median}\left(\widehat{V I X}^{2}\right)_{1994:(t-6)} \\ 0, & \text { otherwise }\end{cases}
$$

$D_{n o n-s t r e s s e d F O M C}= \begin{cases}1, & \text { if } t=F O M C \text { and } \widehat{V I X}_{t-6}^{2} \leq \operatorname{median}\left(\widehat{V I X}^{2}\right)_{1994:(t-6)} \\ 0, & \text { otherwise }\end{cases}$

To test whether (i) meetings held in stressed periods delivered, on average, higher returns than usual days and (ii) whether meetings held in non-stressed periods delivered, on average, higher returns than usual days, the following regression is estimated:

$$
Y_{t}^{j}=\alpha+\beta_{1} * D_{\text {stressedFOMC }}+\beta_{2} * D_{\text {non-stressedFOMC }}+\epsilon
$$


where the dependent variable is constructed using different $j$ windows as in Equation (3-1), and the dummies are those defined in Equations (3-2) and (3-3). Both realized equity returns and the change in the market uncertainty variable will be considered as dependent variables.

Table 3.5 suggests that pre-scheduled meetings deliver higher average returns only in stressed periods. Returns on such days are, on average, 109 bps, and if we consider the window covering the twenty-four hours prior to an FOMC release, the returns are, on average, 128 bps. In our baseline sample, only 23 events out of 60 pre-scheduled announcements are considered FOMC meetings during stressed periods, and they are concentrated between 2007 and 2010. Meanwhile, FOMC meetings during non-stressed periods do not present an average that is significantly higher than usual days, and the estimated coefficients are nearly ten times smaller than those for FOMC meetings during stressed periods, when we consider both total and anticipation movements. Note also that results remain unchanged after controlling for the policy cycle. The 2007-2010 period was marked by interest rate cuts, an attempt by the Fed to rescue the market. Table 3.5 presents results controlling for easing during stressed periods and tightening during non-stressed periods, using interaction terms. ${ }^{1}$

Table 3.5: FOMC Meetings in Stressed vs Non-Stressed Periods and Interaction with Policy Direction

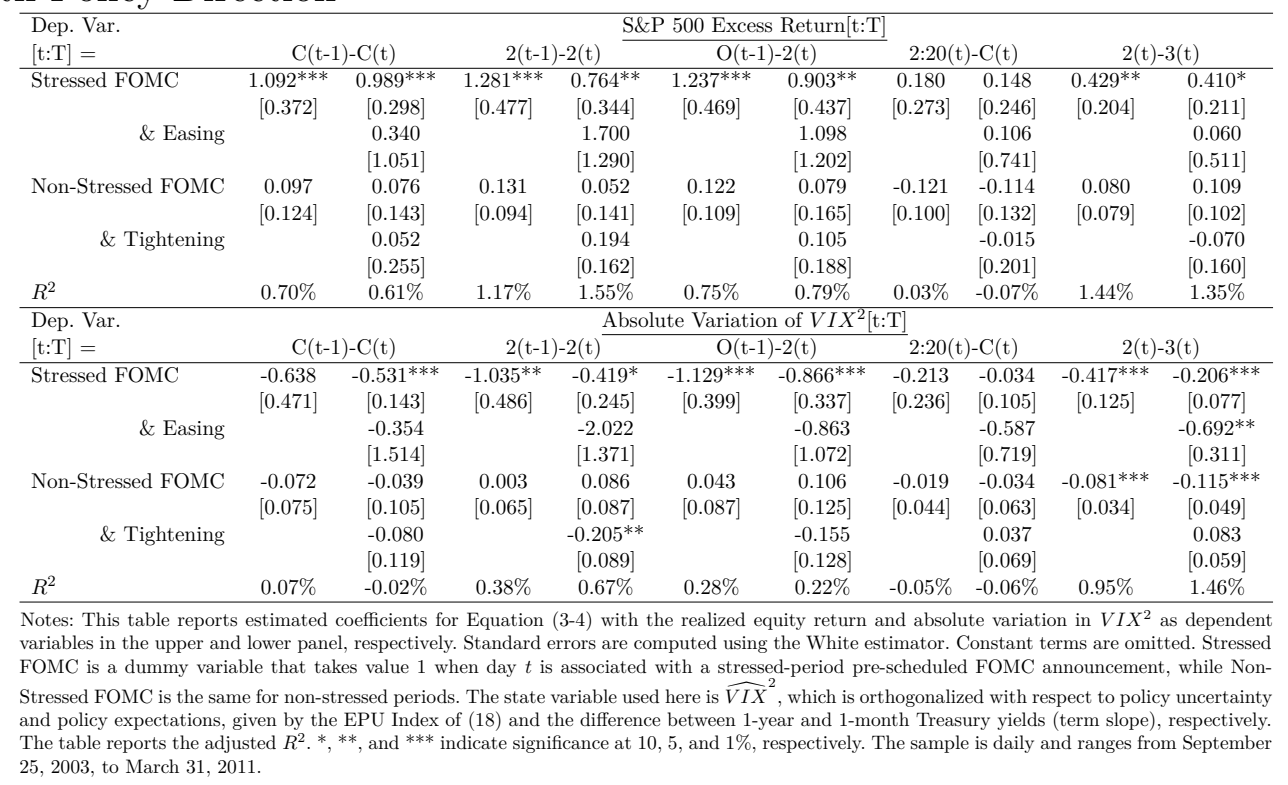

${ }^{1}$ Of 20 meetings held during stressed periods, 7 were followed by interest rate cuts, and none of them were followed by policy tightening. Meanwhile, of 40 FOMC meetings during non-stressed periods, 17 were followed by interest rate hikes, and only 1 featured policy easing. 


\subsection{4}

\section{Uncertainty Resolution}

The second panel of Table 3.5 shows that uncertainty begins to decline hours before the announcement during FOMC held during stressed periods and only during those meetings. This table presents estimates of Equation (34) using one of our proxies for uncertainty resolution - variation in $V I X^{2}$ - as the dependent variable.

Right at the announcement, we have a sudden decline in uncertainty, independent of the period we consider, as there is always information flow at the release. Moreover, this table provides additional support for our priors: (i) higher-than-average equity returns occur on pre-scheduled announcement days that happen when market uncertainty is high; (ii) investors somehow resolve uncertainty hours before the announcement; and (iii) although uncertainty is reduced and asset prices increase immediately after the announcement, this last upward movement is reversed before market closes. Therefore, higher performance associated with investor relief only occurs during stressed periods, and it occurs hours before the announcement.

\subsection{5}

\section{Market Sell-Off}

We now test whether the average positive returns in stressed periods reported in the previous analysis are associated with (i) market sell-offs on previous days or (ii) market sell-offs on the days following the announcement. If not, we can conclude that this effect is not a temporary movement and that it is not reverting a sell-off that occurred prior to the FOMC meeting as the market became increasingly stressed about the announcement.

Table 3.6 addresses these points, showing no evidence of a market selloff before or after the announcement. The same results are obtained if we extend the period considered to many weeks. The cumulative excess return was computed one week before and after the announcement. Equation (3-3) was estimated using lead and lagged excess returns as dependent variables. Note that the level of market uncertainty does not vary significantly on the days before or after the announcement day, suggesting once again that the preFOMC investor relief is not reflecting a short-run increase in market stress.

\section{3}

\section{Cross-Sectional Analysis}

(2) and (7) show that the dispersion in betas can capture the dispersion in industry portfolios' average returns as long as only days of pre-scheduled 
Table 3.6: Market Sell-Off before or after Announcement Window

\begin{tabular}{|c|c|c|c|c|c|c|}
\hline \multirow[t]{3}{*}{ Dep. Var. $=$} & \multicolumn{3}{|c|}{ Realized Equity Return } & \multicolumn{3}{|c|}{ Absolute Variation in $V I X^{2}$} \\
\hline & \multirow{3}{*}{$\begin{array}{c}\text { All } \\
D_{F O M C} \\
0.479^{* * *}\end{array}$} & \multicolumn{2}{|c|}{ Decomposed } & \multirow{4}{*}{$\begin{array}{c}\text { All } \\
D_{F O M C} \\
-0.289 \\
{[0.192]}\end{array}$} & \multicolumn{2}{|c|}{ Decomposed } \\
\hline & & $D_{\text {Stressed }}$ & $D_{\text {Non-Stressed }}$ & & $D_{\text {Stressed }}$ & $D_{\text {Non-Stressed }}$ \\
\hline & & $1.073^{* * *}$ & 0.109 & & -0.626 & -0.080 \\
\hline Ann. Day $=\mathrm{t}$ & {$[0.174]$} & {$[0.374]$} & {$[0.124]$} & & {$[0.472]$} & {$[0.076]$} \\
\hline & $0.572^{* * *}$ & $1.338 * * *$ & 0.095 & $-0.394^{*}$ & $-1.053^{* *}$ & 0.015 \\
\hline $2 \mathrm{pm}(\mathrm{t}-1): 2 \mathrm{pm}(\mathrm{t})$ & {$[0.206]$} & {$[0.473]$} & {$[0.091]$} & {$[0.203]$} & {$[0.484]$} & {$[0.064]$} \\
\hline$\sum_{i=t-20}^{t-1} y_{i}$ & -0.009 & -0.085 & $0.038^{*}$ & 0.009 & 0.022 & 0.000 \\
\hline$\frac{\sum_{i=t-20} y_{i}}{20}$ & {$[0.029]$} & {$[0.061]$} & {$[0.022]$} & {$[0.029]$} & {$[0.072]$} & {$[0.010]$} \\
\hline$\sum_{i=t-15}^{t-1} y_{i}$ & -0.004 & -0.081 & 0.045 & 0.009 & 0.015 & 0.005 \\
\hline$\frac{\sum_{i=t-15^{9}}}{15}$ & {$[0.031]$} & {$[0.062]$} & {$[0.028]$} & {$[0.031]$} & {$[0.078]$} & {$[0.012]$} \\
\hline$\sum^{t-1} y_{i}$ & 0.016 & -0.028 & 0.044 & 0.003 & -0.004 & 0.008 \\
\hline$\frac{\sum_{i=t-10^{9 i}}}{10}$ & {$[0.044]$} & [0.095] & {$[0.038]$} & {$[0.040]$} & {$[0.100]$} & {$[0.018]$} \\
\hline$\sum^{t-1}-y_{i}$ & -0.014 & 0.056 & -0.058 & 0.034 & -0.002 & $0.057^{* *} *$ \\
\hline$\frac{\sum_{i=t-5}{ }^{9 i}}{5}$ & {$[0.059]$} & {$[0.125]$} & {$[0.054]$} & {$[0.074]$} & {$[0.187]$} & {$[0.028]$} \\
\hline$\sum^{t-1} y_{i}$ & 0.002 & 0.090 & -0.051 & 0.006 & -0.096 & $0.069 * *$ \\
\hline$\frac{\sum_{i=t-4} g_{i}}{4}$ & {$[0.063]$} & {$[0.130]$} & {$[0.060]$} & {$[0.046]$} & {$[0.101]$} & {$[0.031]$} \\
\hline$\sum^{t-1} y_{i}$ & -0.034 & -0.056 & -0.021 & 0.046 & 0.031 & 0.056 \\
\hline$\frac{\sum_{i=t-3}{ }^{9 i}}{3}$ & {$[0.066]$} & {$[0.141]$} & {$[0.060]$} & {$[0.056]$} & [0.131] & {$[0.034]$} \\
\hline$\sum^{t-1}$ & 0.035 & 0.027 & 0.040 & -0.099 & -0.268 & 0.006 \\
\hline$\frac{\sum_{i=t-2} y_{i}}{2}$ & {$[0.104]$} & {$[0.246]$} & {$[0.068]$} & {$[0.164]$} & {$[0.415]$} & {$[0.051]$} \\
\hline & 0.133 & 0.388 & -0.024 & -0.263 & -0.813 & 0.078 \\
\hline t-1 & {$[0.227]$} & {$[0.557]$} & {$[0.116]$} & {$[0.315]$} & {$[0.796]$} & {$[0.081]$} \\
\hline & -0.222 & -0.439 & -0.087 & 0.088 & 0.162 & 0.041 \\
\hline$t+1$ & {$[0.183]$} & [0.391] & {$[0.164]$} & {$[0.202]$} & {$[0.494]$} & {$[0.103]$} \\
\hline$\sum_{i=t+1}^{t+2} y_{i}$ & -0.147 & -0.251 & -0.083 & -0.015 & -0.123 & 0.052 \\
\hline$\frac{\sum_{i=t+1}{ }^{9 i}}{2}$ & {$[0.110]$} & {$[0.229]$} & {$[0.103]$} & {$[0.152]$} & {$[0.387]$} & {$[0.048]$} \\
\hline$\sum_{i=3}^{t+3} y_{i}$ & 0.001 & 0.112 & -0.068 & -0.096 & -0.263 & 0.007 \\
\hline$\frac{\sum_{i=t+1} 9 i}{3}$ & {$[0.083]$} & {$[0.184]$} & {$[0.066]$} & {$[0.126]$} & {$[0.322]$} & {$[0.031]$} \\
\hline$\sum^{t+4}$ & -0.035 & -0.013 & -0.049 & -0.088 & -0.249 & 0.010 \\
\hline$\frac{\sum_{i=t+1} g_{i}}{4}$ & {$[0.068]$} & {$[0.153]$} & {$[0.055]$} & {$[0.123]$} & {$[0.314]$} & {$[0.027]$} \\
\hline$\sum_{i=t+1}^{t+5} y_{i}$ & -0.085 & -0.147 & -0.046 & -0.027 & -0.078 & 0.004 \\
\hline$\frac{己_{i=t+1} 9 i}{5}$ & {$[0.058]$} & {$[0.130]$} & {$[0.047]$} & {$[0.076]$} & [0.193] & {$[0.022]$} \\
\hline$\sum_{i=t+1}^{t+10} y_{i}$ & -0.026 & -0.096 & 0.017 & -0.009 & -0.033 & 0.006 \\
\hline$\frac{\sum_{i=t+1} 9 t}{10}$ & [0.035] & {$[0.067]$} & {$[0.036]$} & {$[0.029]$} & {$[0.068]$} & {$[0.017]$} \\
\hline$\sum^{t+15} y_{i}$ & -0.036 & -0.112 & 0.013 & 0.023 & 0.041 & 0.012 \\
\hline$\frac{\sum_{i=t+1} y_{i}}{15}$ & {$[0.038]$} & {$[0.084]$} & {$[0.028]$} & {$[0.030]$} & {$[0.071]$} & {$[0.017]$} \\
\hline$\sum_{i=20}^{t+20} y_{i}$ & -0.019 & -0.054 & 0.004 & -0.002 & -0.024 & 0.012 \\
\hline$\frac{\Omega_{i=t+1}}{20}$ & {$[0.031]$} & {$[0.065]$} & {$[0.026]$} & {$[0.027]$} & {$[0.066]$} & {$[0.013]$} \\
\hline
\end{tabular}

Notes: This table reports estimated coefficients for Equation (3-1) in the All columns and Equation (3-4) in the Decomposed columns. Standard errors, inside brackets, are computed using the White estimator. We use the daily average of the realized equity return and the absolute variation in $V I X^{2}$ on, before and after the announcement for different window specifications. The pre-scheduled announcement days are represented by $t . t-1$, and $t+1$ represents the preceding and posterior days, $2 \mathrm{pm}(\mathrm{t}-1): 2 \mathrm{pm}(\mathrm{t})$ represents the previous 24 hours' movement, and $\sum_{i=t-1}^{t-T} y_{i} / T\left(\sum_{i=t+1}^{t+T} y_{i} / T\right)$ is the average of the dependent variable $T$ days before (after). ${ }^{*}, * *$, and $* * *$ indicate significance at 10,5 , and $1 \%$, respectively. The sample is daily and ranges from September 25, 2003, to March 31, 2011.

monetary policy announcements are considered when computing average returns. After computing the industry portfolios' market $\beta \mathrm{s}$ in the first stage of Fama-Macbeth regressions (using usual days only), the relationship between the $\beta \mathrm{s}$ and the average returns on announcement days is striking, implying that the CAPM predictive returns fit the actual average returns on such days.

Figure 3.5 shows not only that the same result prevails in our baseline sample but also that it is true only during stressed periods. In other words, the industries' market exposure is aligned with the realized average returns of these portfolios only on FOMC meeting days during stressed periods. The risk-return trade-off is clearer on such days, as greater exposure is translated into higher average returns. During non-stressed periods, we do not have any dispersion of predicted daily returns, as the estimated risk premium is only $0.029 \%$, and it is not statistically significant, while it is large $(1.172 \%)$ and 
highly significant in stressed periods. The risk premium on non-stressed days is lower than on usual days, while the average of all announcement days is 0.558\%. Therefore, CAPM appears to work only on stressed announcement days. 
Figure 3.5: CAPM and Industry Portfolios: The Effect of Market Uncertainty

a

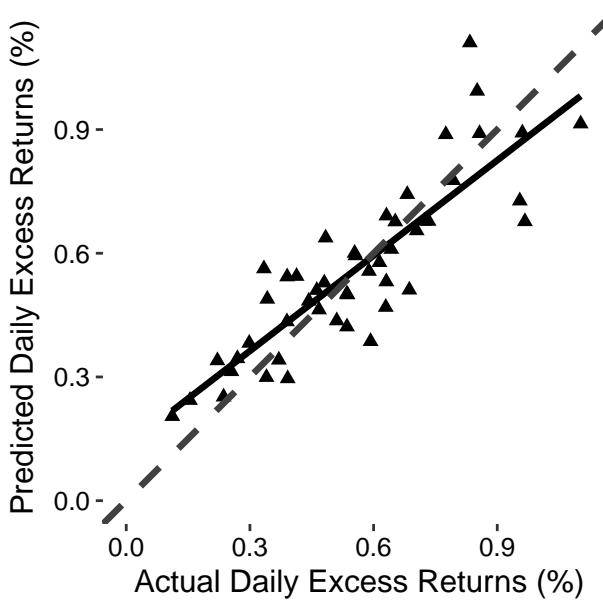

C

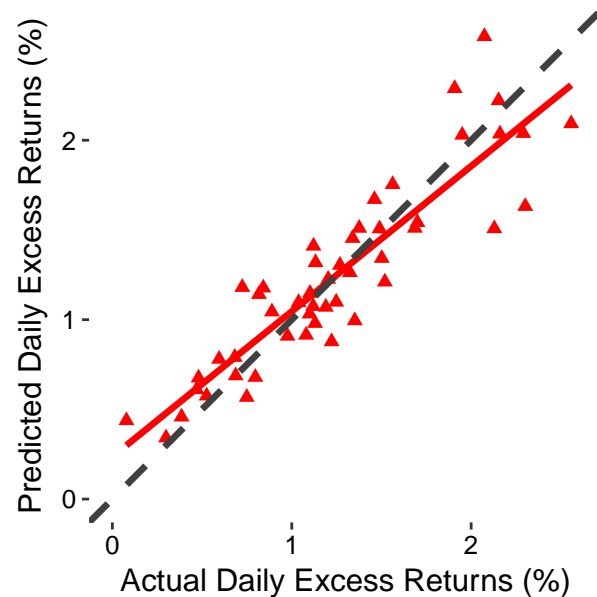

b

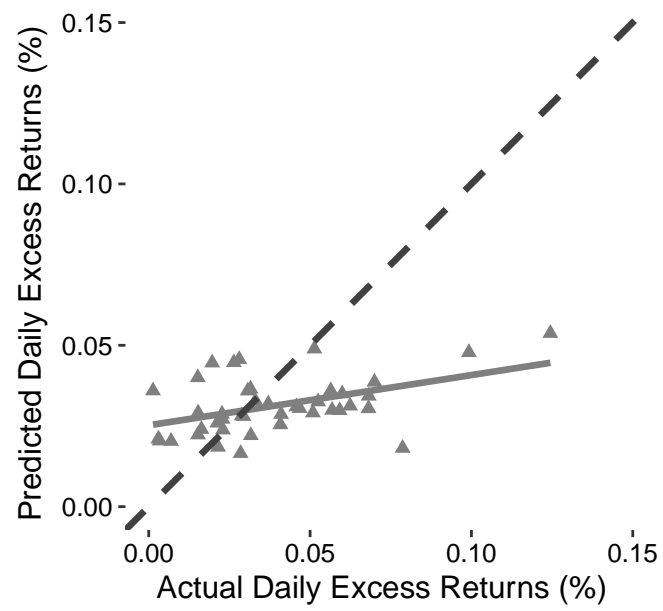

d

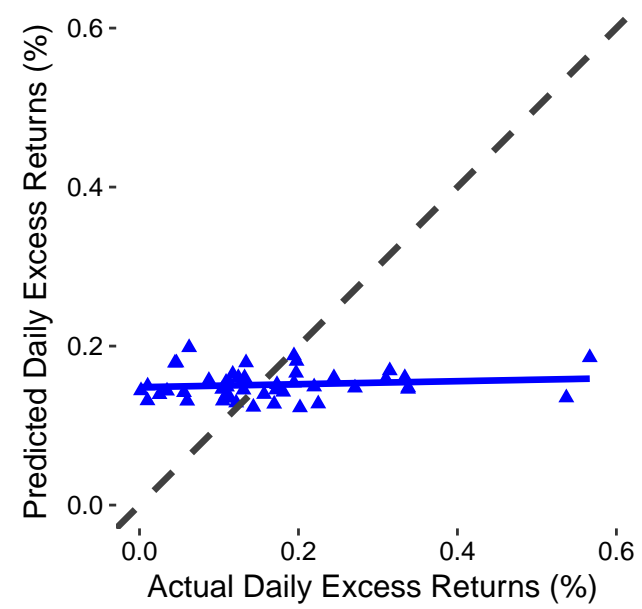

Notes: We plot the predicted against the realized average daily return of 49 industry portfolios available at Kenneth French's website. The prediction model is a simple one-factor model (CAPM). The estimation is given by Fama-Macbeth's two-stage procedure. The industries' $\beta$ s are estimated with the entire sample. In Plot $a$, the average returns are computed considering only days associated with pre-scheduled announcements. Plot $b$ uses only usual days (i.e., it does not consider announcement days). Plot $c$ and Plot $d$ consider only announcements that took place during stressed and non-stressed periods, respectively. The solid lines represent the linear fit, while the dashed line represents the 45-degree line. 


\section{4}

\section{Robustness Analysis and Additional Controls}

In this section, we test whether the previous results are robust to different samples and proxies. We also include additional controls that could explain the patterns we uncovered. The intention here is to show that the previous results hold beyond our selected sample and variables. Our sample selection was based on the availability of all data we consider in the full analysis.

\section{1}

\section{Redefining Announcement Timing}

First, we change how we define the time of the announcements and apply the new definition to all pre-scheduled meetings that took place between September 25, 2003, and March 31, 2011, as before. To do so, we computed returns and changes in volatility relative to the actual time of the announcement using the following timings: twenty-four hours before the meeting and 1 hour and twenty-four hours after the meeting. Note that this methodology is more general than that in the previous section. There, we computed windows of anticipation movement up to $2 \mathrm{pm}$ and adjustment movement from 2:20 pm onward because all the announcements took place closely around 2:15 pm. Here, the windows correspond exactly to the the precise number of hours before and after an announcement. Thus, we can analyze even samples in which some announcements were not close to 2:15 pm.

As the previous results already suggested, the level of market uncertainty can explain the realized equity return observed hours before the announcements. This result is presented again in Table 4.1. Note that even after controlling for variables correlated with a high level of market uncertainty, such as the NBER recession dummy or an easing cycle, the magnitude of the coefficient associated with our market uncertainty proxy does not change significantly. Once again, we find that the greater the policy uncertainty is, the greater the adjustment at the time of the announcement.

Note that uncertainty resolution still occurs before the announcement. This pattern prevails even after adding controls for recessions, policy direction, persistence and alternative drivers. Moreover, the realized return observed right at the announcement during periods with high policy uncertainty also 
comes with uncertainty resolution, as noted by (4). 


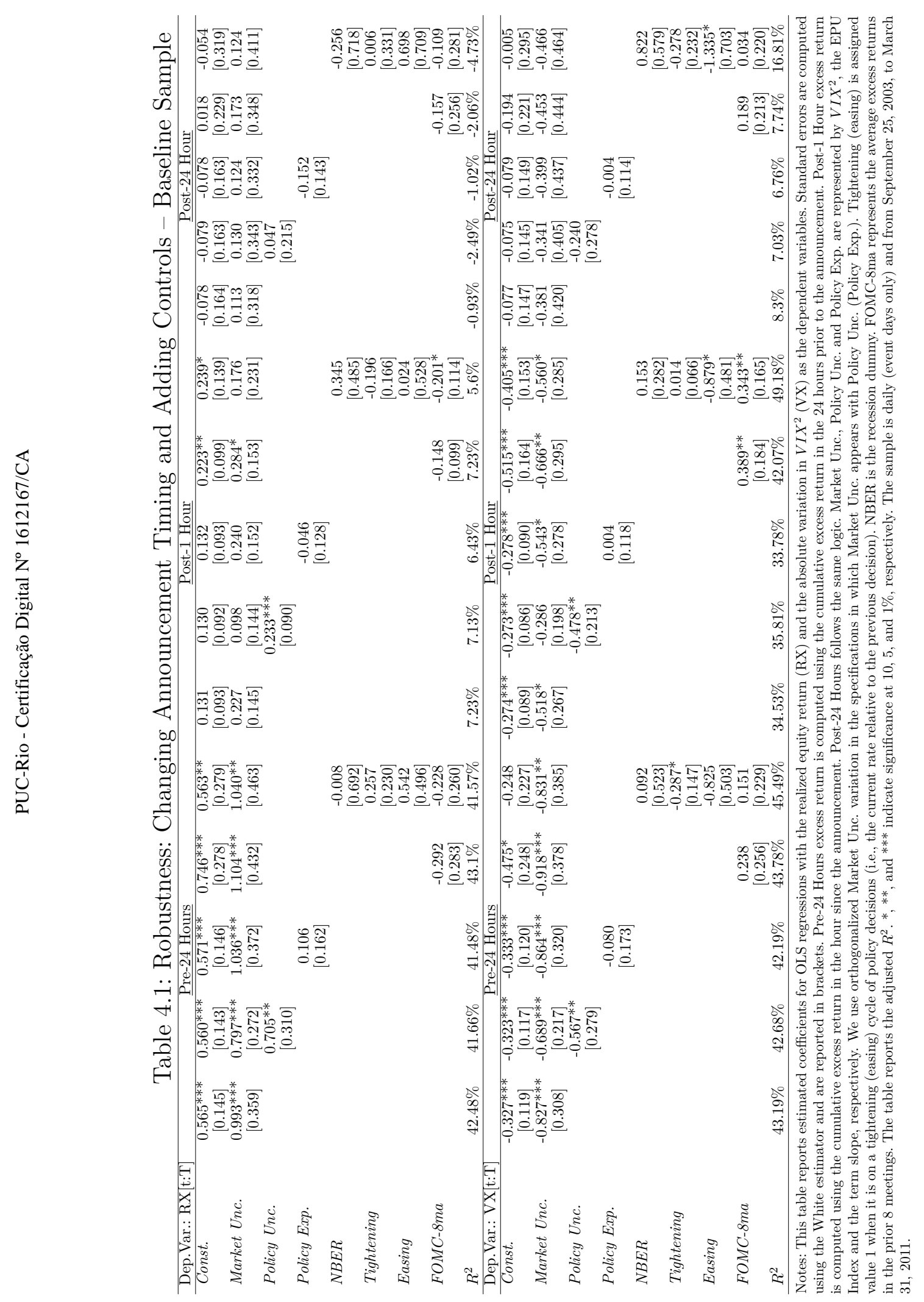




\section{2}

\section{All Scheduled Meetings at 2:15 pm}

Second, we analyze a sample in which all the pre-scheduled meetings took place around 2:15 pm. This sample ranges from September 1994 to March 2011 and is the baseline sample used by (2), the first paper to document the pre-FOMC announcement drift. As presented in Table 4.2, market uncertainty remains a significant conditioning variable. The postannouncement adjustment still presents a significant relationship with policy uncertainty, reflecting the fact that the announcement leads to the resolution of policy uncertainty.

(2) present results suggesting that the realized equity return in the twenty-four hours preceding the announcement has a strong persistent component, such that the average return on the past 8 meetings (FOMC-8ma) was relevant when explaining the differences in realized returns on such days. Once we consider the level of market uncertainty, this significance disappears, suggesting that the return persistence is coming from persistence in market uncertainty. 


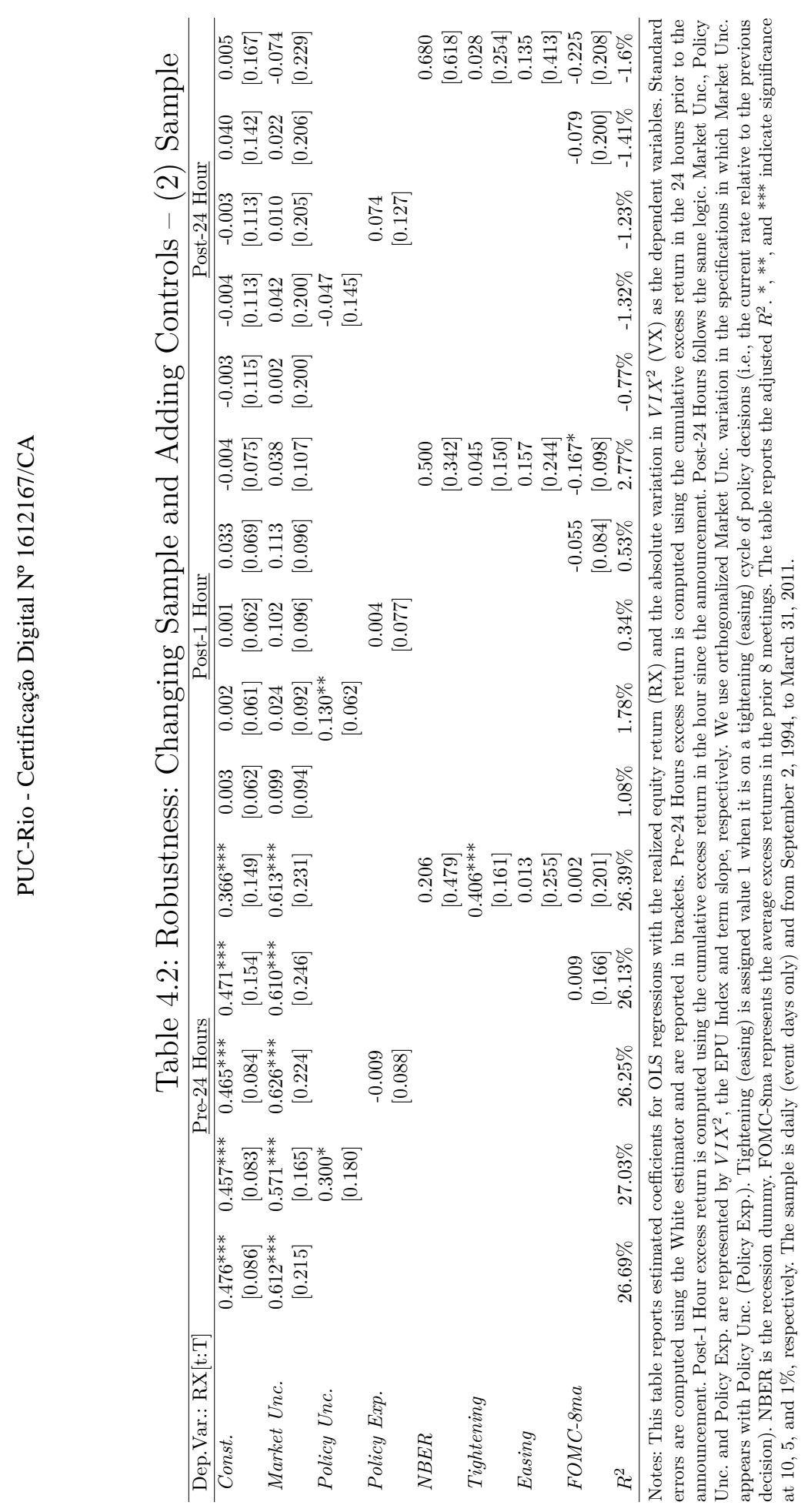




\section{3}

\section{Adding Recent Data (Sep 2003 - Jan 2016)}

Third, we analyze the sample with all pre-scheduled meetings from September 2003 to January 2016. This sample is used in response to recent papers, such as (4). They report that the pre-FOMC drift disappeared in the past decade. Table 4.3 reports the results with the extended sample. The market uncertainty coefficients remain statistically significant when explaining both equity returns and uncertainty realization hours before the announcement. Therefore, the pre-FOMC announcement drift is not necessarily sample specific, but it has been lower due to lower market uncertainty. 


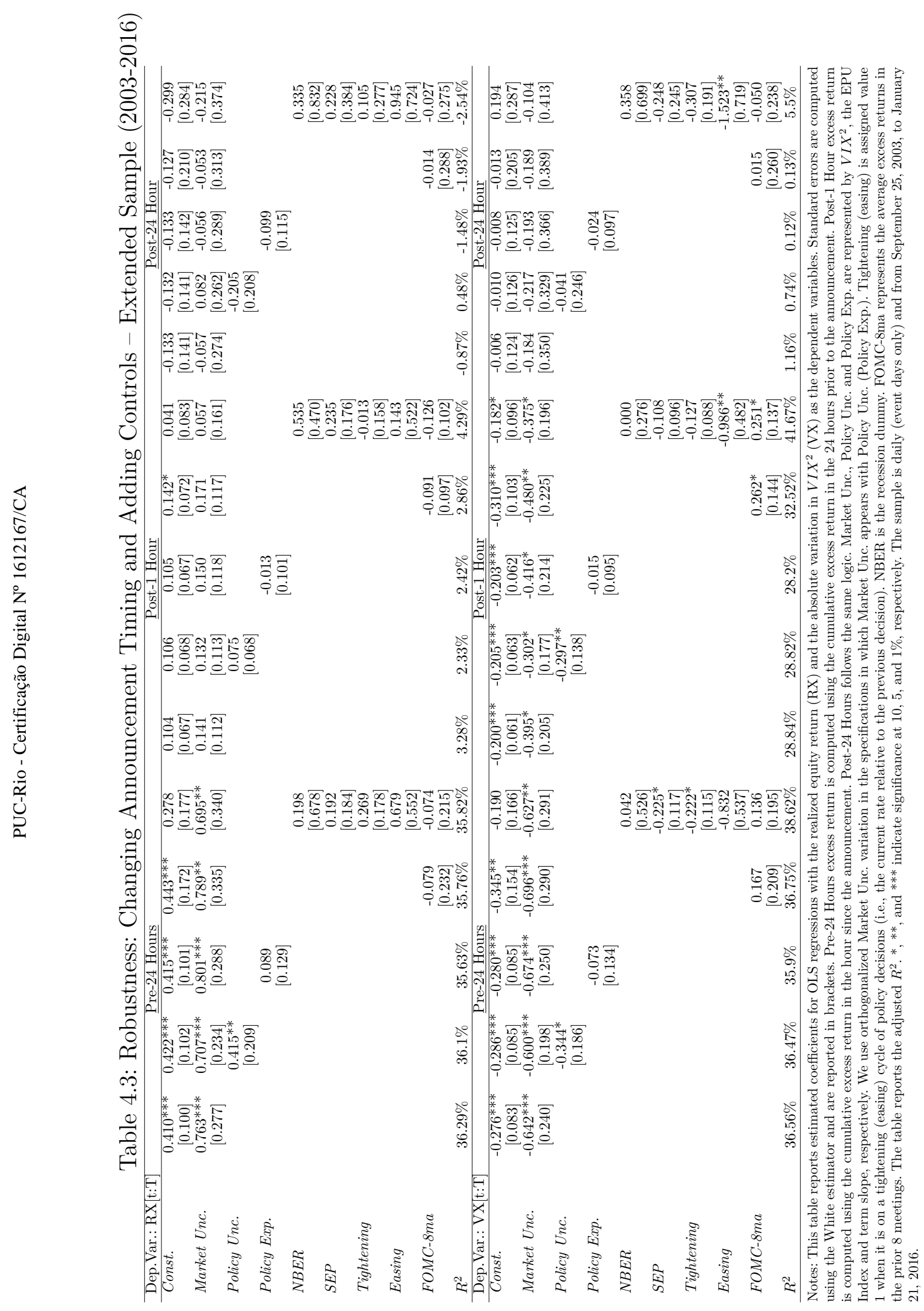




\section{4}

\section{Alternative Market Uncertainty Measures}

Three alternative proxies for market uncertainty are tested here. First, we consider the lower bound of the equity premium proposed by (14), constructed using options and the term structure of interest rates $(E R P)$. Second, we consider the realized variance of market returns over the past month (RVar). Third, we run a more detailed analysis with the variance risk premium. The first two proxies are tested while also considering two measures of policy uncertainty: our baseline measure, the EPU Index proposed by (18) (EPU), and the Implied Volatility of 10-year Treasury Bond Options (TYVIX), as in (13). Once market and policy uncertainty are not orthogonal by construction, we test whether (i) market uncertainty that is orthogonal to policy uncertainty is relevant to explain the anticipation movement and (ii) whether policy uncertainty that is orthogonal to market uncertainty is relevant to explain the same movement.

Table 4.4 presents evidence that the anticipation movement depends on the level of market uncertainty under all proxies and sample specifications. Note also that the explanatory power of policy uncertainty comes from its component associated with market uncertainty. After cleaning the effect of market uncertainty, the significance of the coefficients associated with policy uncertainty disappears. These results are consistent with the view that market uncertainty is robust to these alternative proxies.

Table 4.5 shows that our previous results persist when we consider the variance risk premium as our market uncertainty proxy. ${ }^{1}$ The level of market uncertainty remains relevant, even after controlling for policy uncertainty, policy expectations, persistence, recessions and the monetary policy cycle. We compute the variance risk premium $(V R P)$ as the difference between the riskneutral and physical expectation of market variance. Following the baseline methodology proposed by (15), we model the physical expectation of market variance using a martingale process, i.e., $E\left[\sigma_{t: t+1}^{2}\right]=\sigma_{t-1: t}^{2}$. The risk-neutral measure of expected variance is given by $V I X^{2}$. (15) find evidence that a high (low) variance risk premium is associated with high (low) future equity returns.

\footnotetext{
${ }^{1}$ These calculations ignore a single FOMC announcement that coincided with a negative value of the variance risk premium. We treat this event in October 2008 as an outlier because, in theory, the variance risk premium should always be positive. We observed a spike in realized variance in the days before the announcement that was not necessarily related to the change in the physical expectation of future realized variance. Assuming that the variance risk premium was zero leads to similar returns.
} 
Table 4.4: Alternative Uncertainty Measures and Pre-FOMC Returns Dep. Var.: RX Sample

Window: Pre-24 Hours Baseline Sample $\quad 1 \overline{994-2011}$

Model 1:

$\widehat{E R P}$

$E P U$

TYVIX

Model 2:

$E R P$

$\widehat{E P U}$

$\widehat{T Y V I X}$

Model 3:

$\widehat{R V a r}$

$E P U$

TYVIX

Model 4:

RVar

$\widehat{E P U}$

\section{$\widehat{T Y V I X}$}

$0.762^{* * *} \quad 0.755^{* * *}$

$[0.242] \quad[0.275]$

$0.711^{* *}$

[0.303]

$0.675^{* * *}$

[0.240]

$1.019^{* * *} \quad 1.026^{* * *}$

[0.354]

$-0.092$

[0.352]

[0.128]

$-0.146$

[0.124]

$1.002^{* *}$

[0.457]

$0.614^{* * *}$

[0.218]

$0.958^{* *}$
$[0.449]$

$[0.449]$

$0.722^{* * *}$

[0.277]

$0.275^{* *}$

[0.132]

$0.640^{* * *}$

[0.236]

$1.015^{* * *}$

$1.020^{* * *}$

$0.669^{* * *}$

[0.257]

$-0.080$

2003-2016

$\begin{array}{cc}0.650^{* * *} & 0.513^{* *} \\ {[0.205]} & {[0.218]} \\ 0.417^{* *} & \\ {[0.210]} & \\ & 0.550^{* * *} \\ & {[0.184]}\end{array}$

$[0.184]$

[0.394]

[0.399]

[0.081]

[0.147]

0.071

[0.162]
[0.330]

$0.376^{* * *}$

[0.155]

$0.748^{* * *}$
$[0.265]$

$-0.040$

[0.098]

$0.754^{* * *}$

[0.270]

$-0.062$

[0.107]

$0.743^{* *}$

[0.351]

$0.525^{* * *}$

[0.181]

$0.801^{* * *} \quad 0.806^{* * *}$

[0.306] [0.311]

$-0.036$

[0.102]

0.077

Notes: This table reports estimated coefficients for OLS regressions with realized equity return in the 24 hours preceding pre-scheduled announcements as the dependent variable. The regressors are market and policy uncertainty observed six days before the announcement. Standard errors are computed using the White estimator and are reported in brackets. Constant terms and $R^{2}$ are omitted. Three samples are considered: 09:2003-03:2011 (Baseline), 09:1994-03:2011 ((2)'s sample) and 09:2003-01:2016. The market uncertainty proxies are given by ERP (the lower bound of the equity premium proposed by (14)) and RVar (realized variance over the past month). The policy uncertainty proxies are given by the EPU Index - from (18) - and the TYVIX (the Implied Volatility of 10-year Treasury Bond Options). Wide-hat represents the orthogonalized measure of the named variable, and it is the residual of OLS regression of the respective variable on the other normalized variables. ${ }^{*}, * *$, and $* * *$ indicate significance at 10,5 , and $1 \%$, respectively. 


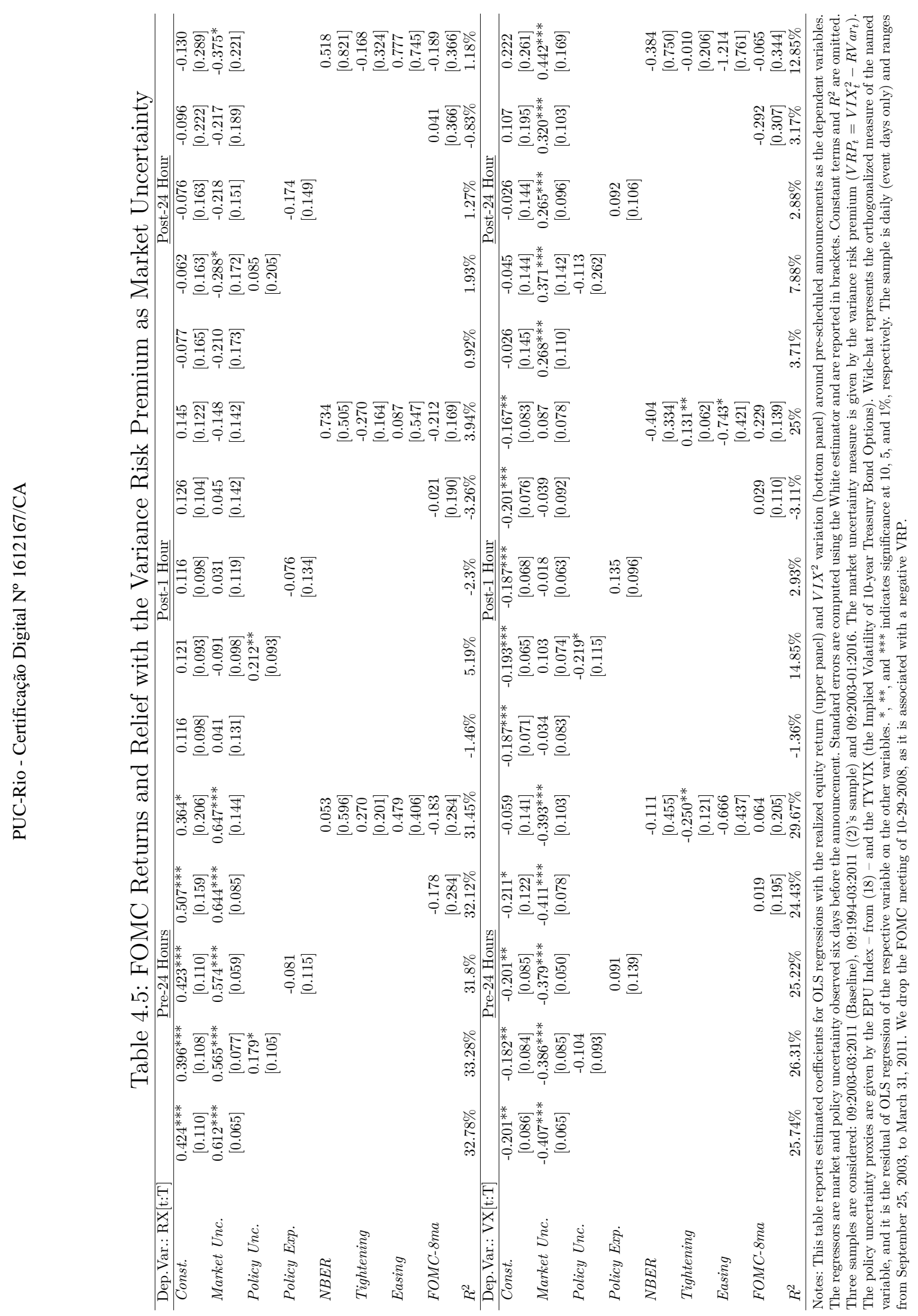




\section{5}

\section{Conclusions}

We show that the pre-FOMC announcement drift in equity returns occurs mostly in periods of high market uncertainty. While we considered other potential drivers such as policy uncertainty and expectations, market uncertainty appears to be the dominant factor. Policy expectations seem to be irrelevant when we attempt to explain the realized equity return around such events, while the direction of the policy decision affects the return after the announcement. Policy uncertainty appears to explain part of the variation in excess returns but only the changes in policy uncertainty that are related to simultaneous moves in market uncertainty. Thus, the magnitude of investor relief is not determined by the uncertainty associated with the upcoming event perse but overall market uncertainty.

Precisely, this abnormal return is explained by a significant reduction in market uncertainty or the risk premium (implied volatility and the variance risk premium) prior to the announcement only when market uncertainty or the risk premium is high, e.g., when it is above its median. Hence, this abnormal return is accompanied by pre-FOMC investor relief. For FOMC meetings held during stressed periods, the cumulative equity return in the hours before the announcement is, on average, $128 \mathrm{bps}$, and it is accompanied by a reduction in priced variance, or investor relief, of $103 \mathrm{bps}$. Both movements are statistically and economically significant. For FOMC meetings held during non-stressed periods, we find neither economic nor statistically significant movements in prices or priced risk. These results persist even after controlling for easing and tightening cycles.

The relevant measures of market uncertainty are quite persistent, as they move slowly with the changes in economic conditions. Markets do not become stressed in the days prior to an announcement, and the resolution of uncertainty is not reversed in the days after the meeting. We do not observe sell-offs even in the weeks prior to the events. This is another indication that policy uncertainty may not be the main driver.

Our analysis also helps us better understand other facts that have been suggested in the recent literature. For instance, we explain why recent studies suggest that the pre-FOMC drift may have disappeared, as this decline in the 
effect is due to time variation that was also present in older data. Additionally, we find that CAPM only works on FOMC dates when the risk premium is high, e.g., implied volatility above its prior median level. We find evidence that only during stressed market periods does there exist a direct relationship between market beta and average daily industry returns.

Our results are robust to different samples and to alternative measures of uncertainty and the risk premium. We consider a list of market uncertainty measures, such as implied variance, the equity premium lower bound from (14), the variance risk premium and the realized variance of market returns over the past month. 


\section{Bibliography}

[1] SAVOR, P.; WILSON, M.. How much do investors care about macroeconomic risk? evidence from scheduled economic announcements. Journal of Financial and Quantitative Analysis, 48(2):343375, 2013.

[2] LUCCA, D. O.; MOENCH, E.. The pre-fomc announcement drift. The Journal of Finance, 70(1):329-371, 2015.

[4] KUROV, A.; GU, C.. Relief rallies after fomc announcements: How much do investors care about uncertainty? 2016.

[4] MEDEIROS, M.; RIBEIRO, R.. When stock returns are predictable: The effect of macroeconomic announcements. 2018.

[5] KROENCKE, T.; SCHMELING, M. ; SCHRIMPF, A.. The fomc risk shift. 2017.

[6] AMENGUAL, D.; XIU, D.. Resolution of policy uncertainty and sudden declines in volatility. Journal of Econometrics, 2017.

[7] SAVOR, P.; WILSON, M.. Asset pricing: A tale of two days. Journal of Financial Economics, 113(2):171-201, 2014.

[8] SAVOR, P.; WILSON, M.. Earnings announcements and systematic risk. The Journal of Finance, 71(1):83-138, 2016.

[9] BOMFIM, A. N.. Pre-announcement effects, news effects, and volatility: Monetary policy and the stock market. Journal of Banking \& Finance, 27(1):133-151, 2003.

[10] BERNANKE, B. S.; KUTTNER, K. N.. What explains the stock market's reaction to federal reserve policy? The Journal of Finance, 60(3):1221-1257, 2005.

[11] KUTTNER, K. N.. Monetary policy surprises and interest rates: Evidence from the fed funds futures market. Journal of Monetary Economics, 47(3):523-544, 2001. 
[12] CIESLAK, A.; MORSE, A. ; VISSING-JORGENSEN, A.. Stock returns over the fomc cycle. 2016.

[13] MUELLER, P.; TAHBAZ-SALEHI, A. ; VEDOLIN, A.. Exchange rates and monetary policy uncertainty. The Journal of Finance, 72(3):1213-1252, 2017.

[14] MARTIN, I.. What is the expected return on the market? The Quarterly Journal of Economics, 132(1):367-433, 2017.

[15] BOLLERSLEV, T.; TAUCHEN, G. ; ZHOU, H.. Expected stock returns and variance risk premia. The Review of Financial Studies, 22(11):44634492, 2009.

[16] KUROV, A.. Investor sentiment and the stock market's reaction to monetary policy. Journal of Banking \& Finance, 34(1):139-149, 2010.

[17] KUROV, A.. What determines the stock market's reaction to monetary policy statements? Review of Financial Economics, 21(4):175-187, 2012.

[18] BAKER, S. R.; BLOOM, N. ; DAVIS, S. J.. Measuring economic policy uncertainty. The Quarterly Journal of Economics, 131(4):1593-1636, 2016. 
A

\section{Measures of Market Uncertainty, Policy Uncertainty and Policy Expectations}

In this section, we provide additional information on our conditioning variables. Table A.1 presents the correlations between all our measures of market uncertainty, policy uncertainty and policy expectations; Figure A.1 depicts their time series. For market uncertainty, the proposed proxies here are (i) $V I X^{2}$; (ii) the variance of the realized return over the past month; (iii) the lower bound of the expected equity premium proposed by (14); and (iv) the variance risk premium as described in (15) - negative values of VRP were considered equal to zero. The third graph of Figure A.1 plots the time series of our policy uncertainty proxies. The black line represents the Economic Policy Uncertainty Index proposed by (18). Meanwhile, on the right y-axis, the blue line represents the level of Implied Volatility of 10-year Treasury Bonds (TYVIX). The fourth graph reports the time series of our policy expectation proxy, given by the difference between 1-year and 1-month Treasury yields (term slope). Note that market and policy uncertainty present positive spikes during recessions (gray shaded areas).

Table A.1: Correlation: Market Uncertainty, Policy Uncertainty and Policy Expectations

\begin{tabular}{ccccccc}
\hline & VRP & ERP & RVar & EPU & TYVIX & Term-Slope \\
\hline VIX & 0.661 & 0.998 & 0.919 & 0.696 & 0.717 & 0.080 \\
$V R P$ & & 0.677 & 0.350 & 0.557 & 0.620 & -0.042 \\
ERP & & & 0.915 & 0.702 & 0.726 & 0.070 \\
$R V a r$ & & & & 0.622 & 0.622 & 0.097 \\
EPU & & & & & 0.650 & 0.057 \\
TYVIX & & & & & & 0.119 \\
\hline
\end{tabular}

Notes: This table reports the correlation between measures of market uncertainty, policy uncertainty and policy expectations. $V I X^{2}$ is the squared value of the Implied Volatility Index (VIX). VRP is the variance risk premium computed as in (15), considering a martingale process for the conditional expectation of realized variance. $E R P$ is the lower bound for the 1-month equity risk premium proposed by (14). RVar is the realized variance of $\mathrm{S} \& \mathrm{P} 500$ returns over the past month. EPU represents the Economic Policy Index proposed by (18), while TYVIX is the 10-year Treasury Bond Option Implied Volatility Index. Term Slope represents our policy expectation proxy, given by the difference between 1-year and 1-month Treasury yields. The sample period is from September 25, 2003, to March 31, 2011. 
Figure A.1: Time Series of Market Uncertainty, Policy Uncertainty and Policy Expectations
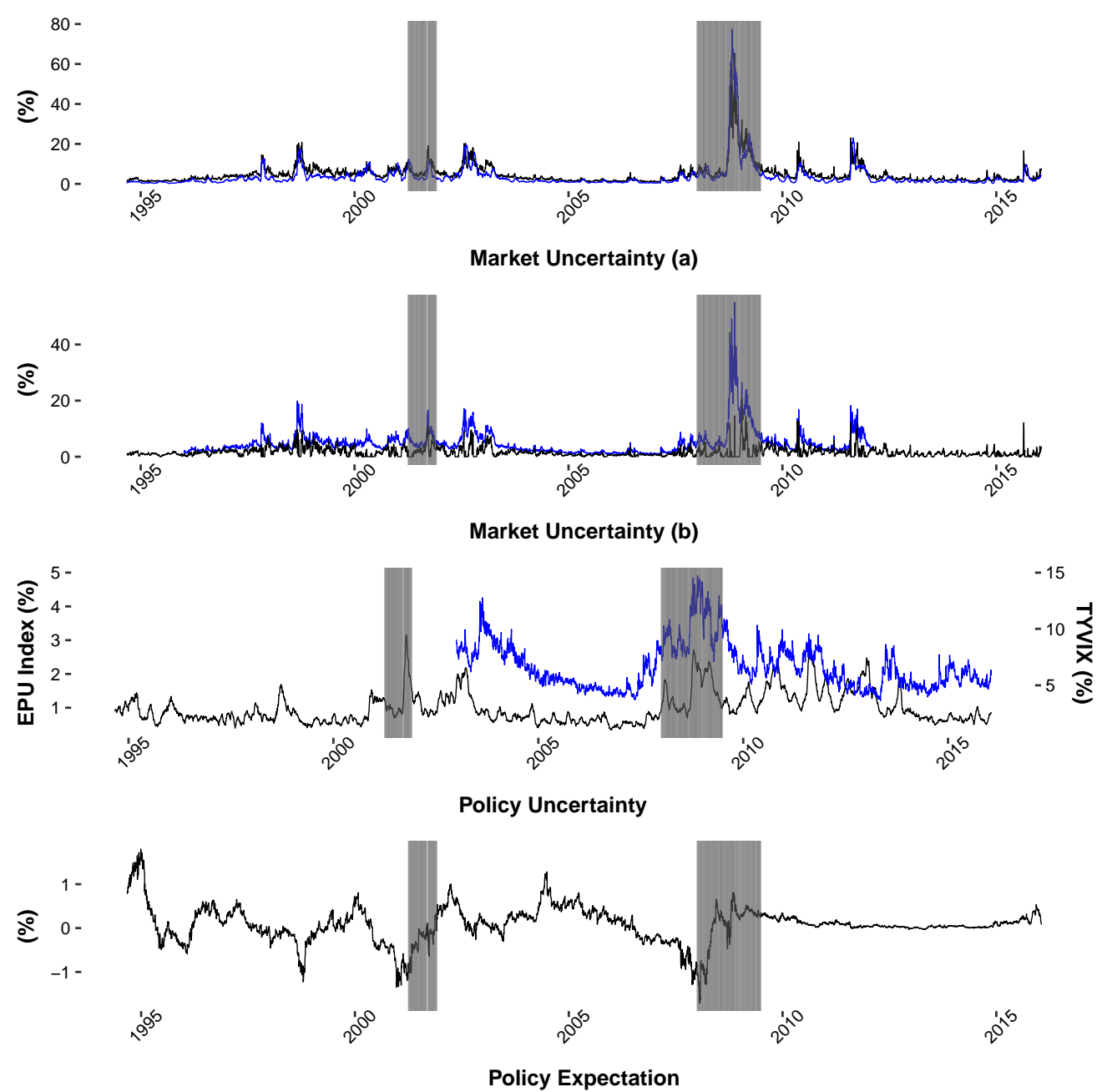

Notes: This figure reports the time series of measures for (i) market uncertainty, (ii) policy uncertainty and (iii) policy expectations, in separate panels. For market uncertainty, four different series are reported: the implied variance $\left(V I X^{2}\right)$ of the S\&P 500 Index (black line) and the realized variance ( $R$ Var $)$ of the $\mathrm{S} \& \mathrm{P} 500$ return over the past month (blue line) are reported on top panel, while the variance risk premium as described in (15) (black line negative values considered equals to zero) and the equity premium lower bound (ERP) from (14) (blue line) are reported on the second panel. The third graph shows the time series of policy uncertainty, which is proxied by the Economic Policy Uncertainty Index (EPU) from (18) - black line, left axis - and the 10-year Treasury Bond Option Implied Volatility Index (TYVIX) - blue line, right axis - and the forth graph reports the time-series of policy expectations given by the difference between 1-year and 1-month Treasury yields (Term Slope). The shaded areas represent NBER recessions according to the St. Louis Fed's database. The sample is from September 3, 1994, to January 21, 2016. 


\section{B \\ FOMC Cycle}

In this section, we present results linking the FOMC Bi-Weekly Return Cycle, as suggested by (12), to market uncertainty. (12) argue that market returns are not concentrated only on pre-scheduled announcement days, as returns are higher than average on even weeks of the FOMC Cycle. Intermeeting weeks present a bi-weekly pattern where returns in excess of the risk free rate are higher than average on weeks $0,2,4$ and 6 .

Figure B.1 shows that the bi-weekly pattern suggested by (12) is only present in stressed periods. The graph reports the 5-day rolling average of the market excess returns, starting on the announcement day (day 0) up to thirtieth business day after the meeting. The same bi-weekly pattern suggested by (12) is present in our sample, as seen on the upper graph. However, only stressed periods present the same but stronger pattern, while the effect is not clear in non-stressed periods. In non-stressed periods, we do not observe a clear pattern anymore. This weaker pattern is not aligned with the pattern in the stressed periods as returns do not follow the same cycle and are rarely negative. 
Figure B.1: FOMC Cycle - Bi-weekly Pattern

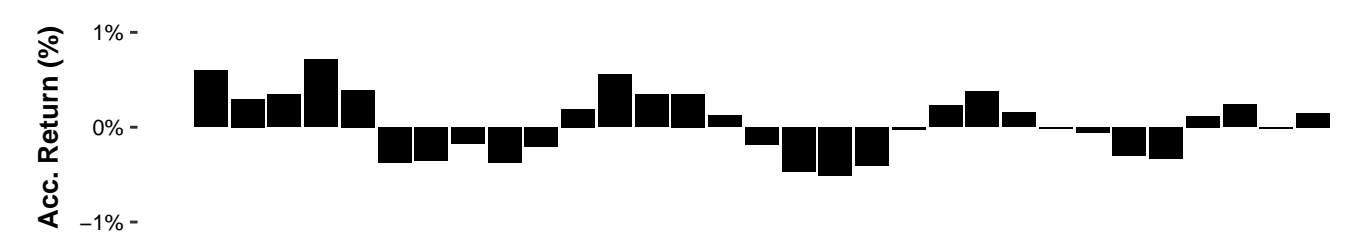

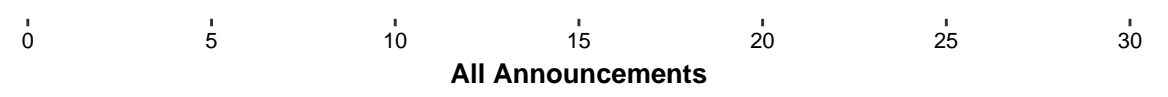
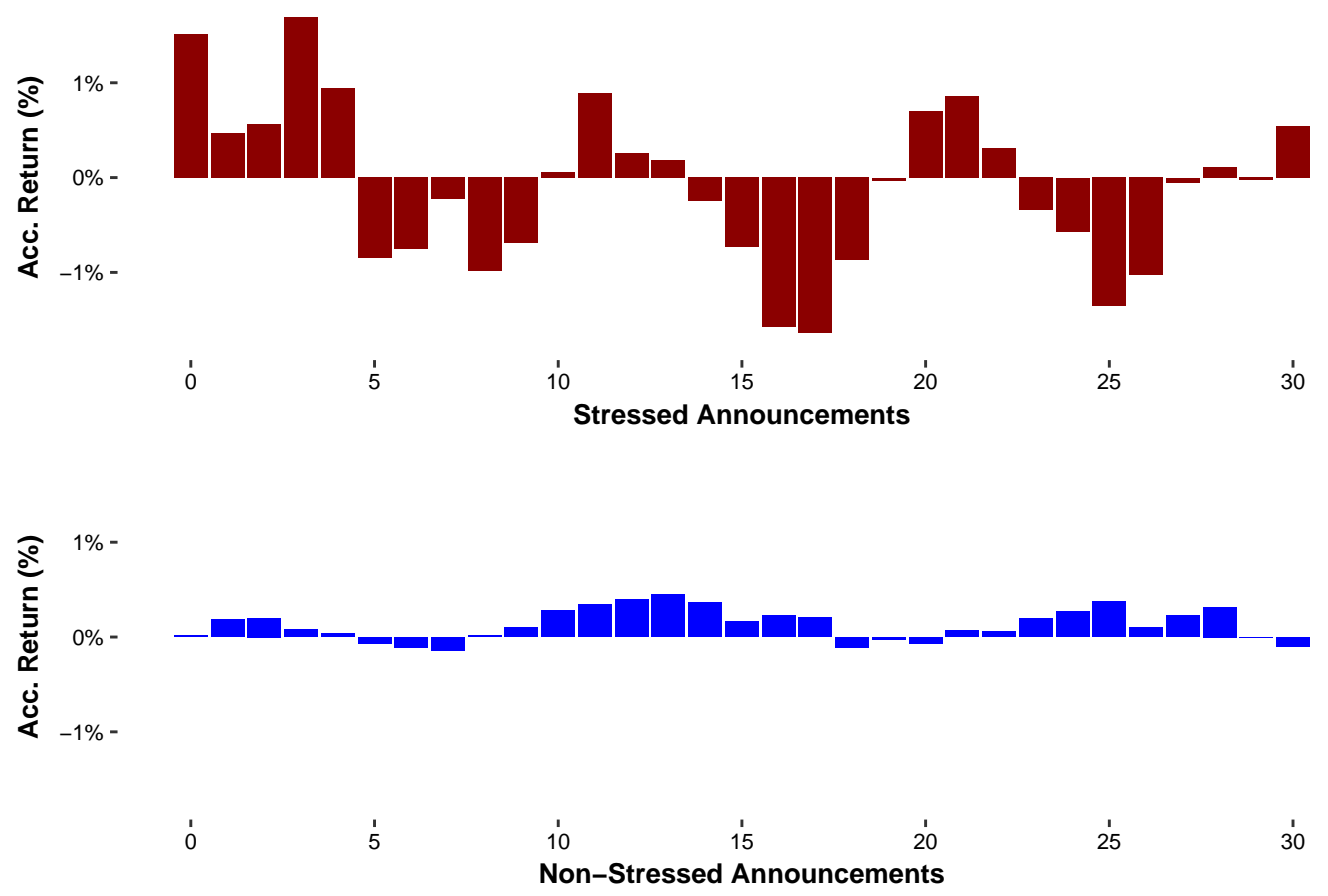

Notes: This figure reports the 5-day rolling average of market excess returns around the FOMC cycle. The excess return is given by the S\&P 500 return over 1-month Treasury bills rate. FOMC cycle is defined as the inter-meeting period, starting on the announcement day and ending on the thirtieth business day after the announcement. The upper graph (black bars) considers all FOMC announcements. The middle graph (red bars) considers only FOMC announcements that took place during stressed periods. The bottom graph (blue bars) considers only FOMC announcements that took place during non-stressed periods. The sample period ranges from September 25, 2003 to March 31, 2011. 